\title{
An Experimental Study of the (Ti-6Al-4V)-xH Phase Diagram Using In Situ Synchrotron XRD and TGA/DSC Techniques
}

\author{
Pei Sun ${ }^{a}$, Z. Zak Fang ${ }^{\text {a, }}$, Mark Koopman a , James Paramore ${ }^{\text {a }}$, K. S. Ravi Chandran ${ }^{\text {a }}$, \\ Yang Ren ${ }^{\mathrm{b}}$ and Jun $\mathrm{Lu}^{\mathrm{c}}$ \\ ${ }^{a}$ Department of Metallurgical Engineering, University of Utah, Salt Lake City, Utah 84112, \\ USA \\ ${ }^{\mathrm{b}}$ X-ray Science Division, Advanced Photon Source, Argonne National Laboratory, 9700 \\ South Cass Avenue, Lemont, IL 60439, USA \\ ${ }^{c}$ Chemical Science and Engineering Division, Argonne National Laboratory, 9700 South \\ Cass Avenue, Lemont, IL 60439, USA \\ * Corresponding author e-mail address: zak.fang@utah.edu
}

\begin{abstract}
Hydrogen has been investigated for decades as a temporary alloying element to refine the microstructure of Ti-6Al-4V, and is now being used in a novel powder metallurgy method, Hydrogen Sintering and Phase Transformations (HSPT). In earlier work from the literature, pseudo-binary phase diagrams of (Ti-6Al-4V)-xH have been studied and developed, but they are not well established due to limitations of their methodologies. In this paper, in situ studies of phase transformations during hydrogenation and dehydrogenation of (Ti-6Al-4V)-xH alloys were conducted using high energy synchrotron X-ray diffraction (XRD), thermal gravimetric analysis (TGA) and differential scanning calorimetry (DSC). The eutectoid phase transformation of $\beta \leftrightarrow \alpha+\delta$ was observed in the (Ti-6Al-4V)-xH alloy via in situ synchrotron XRD at $211^{\circ} \mathrm{C}$ with a hydrogen concentration of 37.5 at.\% (measured using TGA-DSC). The relationships of hydrogen composition to partial pressure and temperature were investigated in the temperature range of 450 to $900{ }^{\circ} \mathrm{C}$. Based on these results, a partial pseudo-binary phase diagram of (Ti-6Al$4 \mathrm{~V})-\mathrm{xH}$ is proposed for hydrogen compositions up to 60 at.\% in the temperature range of 100-
\end{abstract}


$900{ }^{\circ} \mathrm{C}$. Using the data collected in real time under controlled parameters of temperature, composition and hydrogen partial pressure, this work characterizes relevant phase transformations and microstructural evolution for practical titanium-hydrogen technologies of Ti$6 \mathrm{Al}-4 \mathrm{~V}$.

\section{Introduction}

Hydrogen is generally undesired in metals as structural materials, owing to the well-known phenomenon of hydrogen embrittlement in most metallic materials, including titanium and titanium alloys. Pure Ti is less susceptible to hydrogen than many other metals. Pure Ti has been shown to exhibit good ductility in tension with compositions up to 25 at.\% hydrogen [1], although hydrogen still has detrimental effects in notched testing, or under high strain rates, or in Ti materials with large grain sizes [2-5]. For most common titanium materials, ASTM standards require hydrogen concentration to be less than $150 \mathrm{ppm}[6,7]$. Fortunately, due to the fast diffusion of hydrogen in titanium and the reversible nature of reactions between hydrogen and titanium [8], hydrogen concentration can be easily reduced to this safe level by annealing Ti in vacuum or inert gases. This characteristic of hydrogen in $\mathrm{Ti}$ also makes it possible to use hydrogen as a temporary alloying element to refine microstructures, and thus, the mechanical properties of titanium and titanium alloys.

In fact, during the past three decades, hydrogen has played a central role in several advanced titanium processes. A primary powder production method for titanium is known as the hydridedehydride $(\mathrm{HDH})$ process. In this process, in order to crush bulk titanium metal more effectively, Ti is hydrogenated to form titanium hydride $\left(\mathrm{TiH}_{2}\right)$, which is more brittle than titanium metal, facilitating comminution during powder processing [9]. In another example, hydrogen has been used to refine microstructure and improve mechanical properties. This method is referred to as 
thermohydrogen processing (THP), and was first developed by U. Zwicker and H. W. Scheicher in 1957 to improve titanium's workability and deformability during hot working [10]. In the early 1980s, W. R. Kerr et al. reported fine microstructures produced via THP and conducted a comprehensive study on the effects of processing parameters on the final microstructure and tensile properties $[11,12]$. Subsequently, the THP process was investigated extensively for both wrought titanium and powder metallurgy (PM) titanium [13-24].

Recently, the present authors developed a new method for sintering titanium in a hydrogen atmosphere, while controlling phase transformations and microstructure to simultaneously achieve nearly-full densification and refined microstructure in the as-sintered state. This process is thus termed the "hydrogen sintering and phase transformation (HSPT) process" [25, 26].

Although the advantages of adding hydrogen as a temporary alloying element to Ti-6Al-4V have been investigated and reported, the pseudo-binary phase diagrams of (Ti-6Al-4V)-xH that have been presented have not been thoroughly studied or well established. Metal-hydrogen systems, including $\mathrm{Ti}-\mathrm{H}$ and $(\mathrm{Ti}-6 \mathrm{Al}-4 \mathrm{~V})-\mathrm{xH}$, are more challenging to characterize than many metal-metal phase relationships, since the equilibrium hydrogen content varies significantly with not only the temperature, but also the partial pressure of hydrogen. Within the pressure range from sub-atmospheric to several bar, the hydrogen pressure must be considered in order to describe the phase equilibrium of metal-hydrogen at a certain temperature [27]. Materials have often been quenched from high temperatures to ambient temperature in order to "freeze" microstructures and thereby determine the phases that were present at elevated temperatures. However, the strong dependence of phase compositions on hydrogen partial pressure in the Ti-H system, combined with the high mobility of hydrogen through interstitial lattice sites of titanium, make it very difficult to lock hydrogen in place using traditional quenching methods. Since 
hydrogen can be quickly absorbed or desorbed during cooling, depending on the atmosphere and temperature, research methods for sealing hydrogen and phase composition have been sought.

In the first published (Ti-6Al-4V)-xH phase diagram by W. R. Kerr et al. in 1980 (black lines in Fig. 1), hydrogenated samples were sealed in silica tubes to lock hydrogen for microstructural investigations [11]. However, the hydrogen content would still have changed, because of the existence of the free volume in the tubes, and the Ti samples would have absorbed hydrogen during cooling. This would consequently result in non-uniform hydrogen distribution in the samples, e.g. higher hydrogen contents near the surface of the samples. As shown in Fig. 1, W. R. Kerr's work nonetheless demonstrated a eutectoid transformation at $800{ }^{\circ} \mathrm{C}$ [11]. In 2001, J. I. Qazi et al. added a two-phase $\beta+\delta$ field in the phase diagram (red lines in Fig. 1) [22]. In their work, hydrogenated samples were intentionally reacted with oxygen to form an oxide layer to prevent hydrogen loss during heating to $940{ }^{\circ} \mathrm{C}$ [22]. However, in situ XRD results of heating pre-oxidized $\mathrm{TiH}_{2}$ powder in $\mathrm{Ar}$ suggested that oxygen starts to diffuse into the core from the oxide shell on the powder at around $500{ }^{\circ} \mathrm{C}$ [28], which would increase the beta transus temperature and influence the phase transformations. In 2007, C. C. Shen et al. used a Sievert's apparatus to investigate the relationship between pressure, composition and temperature (blue lines in Fig. 1) [24]. The phase identifications were not completely convincing because they were determined by ex-situ XRD at room temperature. In addition, A. A. Ilyn et al. reported a phase diagram (green lines in Fig. 1) that included the formation of the titanium hydride phase below $300^{\circ} \mathrm{C}$ [17], however, no description of the method for determining the phase diagram was given. While all of these efforts have served to move understanding of the (Ti-6Al-4V)-xH system forward, their results are quite divergent, and aspects of underlying physiochemical processes indicate the possibility for alternate methods. 
Given the industrial relevance of this materials system, it is desirable to develop a more accurate near equilibrium (Ti-6Al-4V)-xH phase diagram, using a direct approach to determine equilibrium phases at elevated temperatures in hydrogen atmosphere with controlled partial pressures of $\mathrm{H}_{2}$. In this work, a high energy synchrotron X-ray source was used to determine equilibrium phases in titanium materials in situ at high temperatures and at various hydrogen pressures. Compared with conventional laboratory XRD techniques, high energy synchrotron radiation has a larger penetration depth and better spectral resolution in metallic materials, and allows direct observation of equilibrium phases in bulk Ti-6Al-4V during hydrogenation or dehydrogenation. Further, its high acquisition rate provides a clear observation of the sequence of phase transformations in real time under changing conditions of temperature or partial pressure of hydrogen. The objective of this work was to determine critical phase boundaries affecting the microstructure of the (Ti-6Al-4V)-xH alloy during cooling from temperatures above $1000{ }^{\circ} \mathrm{C}$. In order to determine the exact hydrogen content that corresponds to phase change temperatures, thermal gravimetric analysis (TGA) and differential scanning calorimetry (DSC) were also employed.

\section{Experimental Procedure}

TGA-DSC and in situ X-ray are used to study near equilibrium hydrogen concentrations and corresponding equilibrium phases. The TGA and DSC experiments were carried out simultaneously in an SDT Q600 (TA Instruments). The precision of the thermobalance on this instrument is $0.0001 \mathrm{mg}$. Synchrotron XRD experiments were performed in situ on the 11-ID-C beam-line at the Advanced Photon Source, Argonne National Laboratory, with high energy (115 $\mathrm{keV}$, wavelength $=0.1080 \AA$ ) $\mathrm{X}$-ray illumination. Fig. 2 shows a schematic of the test setup for in situ X-ray experiments. Thin pieces of Ti-6Al-4V were placed on a molybdenum boat within a 
single crystal sapphire tube (ID $8 \mathrm{~mm} \times$ OD $10 \mathrm{~mm} \times \mathrm{L} 216 \mathrm{~mm}$ ), and heated in a small customized furnace. The energy of the synchrotron X-ray source at 11-ID-C is sufficiently high to penetrate through the titanium samples and the walls of the sapphire tube. Patterns from XRD were collected using a 2-D detector, and were observed as a series of rings. Small square lead plates were attached to the detector to remove diffraction points caused by the single crystal sapphire tube. The 2-D diffraction patterns were collected every 20 seconds, and then integrated and converted to 1-D XRD patterns (Fig. 3) using the Fit2D software.

\subsection{Determining phase relationships above $450^{\circ} \mathrm{C}$}

The wrought Ti-6Al-4V ELI rod used for phase analysis was purchased from Onlinemetals.com (cylindrical stock with $12.7 \mathrm{~mm}$ diameter, 0.13 wt.\% O) was cut into thin pieces with a thickness of $\sim 0.5 \mathrm{~mm}$. The microstructure of the starting material is shown in Fig. 4. Isothermal hydrogenation of Ti-6Al-4V was conducted at $550{ }^{\circ} \mathrm{C}, 650{ }^{\circ} \mathrm{C}, 750{ }^{\circ} \mathrm{C}, 800{ }^{\circ} \mathrm{C}$ and $850{ }^{\circ} \mathrm{C}$ in hydrogen atmosphere and synchrotron $\mathrm{X}$-ray illumination. The partial pressure of hydrogen was controlled by adjusting hydrogen and argon mass flow controllers with $\pm 1.5 \%$ accuracy. Specimens were first heated to the target temperature in flowing argon, and then hydrogenated at different hydrogen to argon $\left(\mathrm{H}_{2} / \mathrm{Ar}\right)$ ratios from $5 \%$ to $100 \%$. Ultra high purity hydrogen $\left(\mathrm{O}_{2}<1\right.$ ppm, $\left.\mathrm{H}_{2} \mathrm{O}<2 \mathrm{ppm}\right)$ and $\operatorname{argon}\left(\mathrm{O}_{2}<1 \mathrm{ppm}, \mathrm{H}_{2} \mathrm{O}<1 \mathrm{ppm}\right)$ were used in all experiments in the present study to minimize oxidization. At any given $\mathrm{H}_{2} / \mathrm{Ar}$ ratio, once equilibrium was established, which is indicated by stable position and intensity of XRD peaks, the $\mathrm{H}_{2} / \mathrm{Ar}$ ratio was incrementally increased. After the final hydrogenation step, hydrogenated samples were furnace-cooled to room temperature in flowing Ar. After hydrogenation, samples

were polished and etched (etching reagent: $2 \mathrm{ml} \mathrm{HF}+4 \mathrm{ml} \mathrm{HNO}_{3}+100 \mathrm{ml} \mathrm{H}_{2} \mathrm{O}$ ) to examine 
microstructure. Samples were also dehydrogenated in TGA-DSC to measure mass change and determine remaining hydrogen content.

Similar isothermal hydrogenation experiments were performed in the TGA-DSC from 450$900{ }^{\circ} \mathrm{C}$. The $\mathrm{H}_{2} / \mathrm{Ar}$ ratios were controlled at/under $50 \%$ (limited by the capability of the TGA/DSC unit). The equilibrium hydrogen contents were obtained directly from the weight gain curves of the TGA-DSC measurements. A flat weight gain curve indicated that the approximate equilibrium hydrogen content had been reached. An abrupt change of the weight gain indicated that equilibrium content was changing due to the change in hydrogen pressure $\left(\mathrm{H}_{2} / \mathrm{Ar}\right.$ ratio). As an example, Fig. 5a shows isothermal hydrogenation results at $550{ }^{\circ} \mathrm{C}$. The equilibrium hydrogen concentration, 1.187 wt.\% (36.0 at.\%), was reached within 2 hours in 5\% $\mathrm{H}_{2}$. Subsequently, the hydrogen ratio was increased to $10 \%$, which caused the weight gain curve to increase. Peaks of the heat flow curve corresponding to the weight gain curves indicated that possible phase transformations had occurred. When this information is combined with the in situ XRD spectrum, indicating which phases were present before and after the same physical conditions, the precise phase transformation could be identified. Note that the "jumps" on the TGA and DSC curves at the beginning of hydrogenation with $5 \% \mathrm{H}_{2}$ in Fig. 5a were attributed to an unstable hydrogen flow rate when the mass flow controller was first turned on.

\subsection{Determining phase relationships below $450^{\circ} \mathrm{C}$}

Hydrogen has high mobility and rapid long range diffusion kinetics in titanium above $450{ }^{\circ} \mathrm{C}$, thus the experimental techniques described above are adequate. The above methodology is, however, more difficult to apply at lower temperatures due to slower long range diffusion of hydrogen in Ti. At these lower temperatures, however, hydrogenated Ti-6Al-4V is known to be stable, i.e. it does not dehydrogenate until heated to above a certain temperature. This indicates 
that heating or cooling (Ti-6Al-4V)-xH alloys in flowing argon in a TGA-DSC instrument and/or in an in situ X-ray set up at low temperatures could be used to study phase transformations at fixed hydrogen content.

Therefore, the same Ti-6Al-4V ELI rod was cut into small discs with a thickness of $4 \mathrm{~mm}$, and then hydrogenated to contain different hydrogen contents by varying the hydrogen to argon ratio and temperature. After hydrogenation, samples were furnace-cooled to room temperature in flowing argon. These samples then contained fixed hydrogen contents and could be used to study phase transformation at temperatures below $450{ }^{\circ} \mathrm{C}$. To accomplish this, the hydrogenated specimens were crushed into small pieces, of which 20-30 mg were heated slowly in argon. Phase changes during this process were detected and measured by TGA-DSC, as well as in situ XRD. When the temperature reached a certain value, the sample would initiate dehydrogenation. The samples were fully dehydrogenated by continuously heating to $850{ }^{\circ} \mathrm{C}$, and the total measured weight loss was used to determine the hydrogen content in the sample before dehydrogenation and phase transformation.

\section{Results and discussion}

\subsection{Determining the (Ti-6Al-4V)-xH phase diagram above $450^{\circ} \mathrm{C}$}

\subsubsection{Phase transformations during isothermal hydrogenation at $550{ }^{\circ} \mathrm{C}$}

Equilibrium hydrogen contents were measured by TGA-DSC for samples in 5\%, 10\%, 20\%, $35 \%$ and $50 \%$ hydrogen at $550{ }^{\circ} \mathrm{C}$, and the results are presented in Fig. 5a. Significant hydrogen absorption was observed when hydrogen ratios were 5\% and 35\%, 1.187 wt.\% (36.0 at.\%) and 0.763 wt.\% (26.4 at.\%), respectively, and these relative mass gains were much more than those at the other hydrogen ratios (i.e. $10 \%, 20 \%$ and 50\%). In addition, longer times were required to 
reach equilibrium at these two ratios. The mass gains, i.e. hydrogen uptakes, indicate either dissolution of hydrogen in $\mathrm{Ti}$ or the formation of new phases which are determined by using the in situ XRD techniques. The two peaks associated with the formation of new $\beta$ phase at $5 \% \mathrm{H}_{2}$ and $\delta$ phase at $35 \% \mathrm{H}_{2}$ are presented in the corresponding XRD results, Fig. 5b. The newly formed phases had a larger hydrogen solubility than the original phases $(\beta>\alpha, \delta>\beta)$, and thus were able to absorb a significant amount of hydrogen when transformations of $\alpha \rightarrow \beta$ and $\beta \rightarrow \delta$ occurred. Note that there is a shift of the $\beta$ phase peaks in the X-ray spectra which will be discussed below. Based on the data collected from both the TGA and XRD experiments, a series of phase transformations during hydrogenation at $550{ }^{\circ} \mathrm{C}$ were determined. The sequence of those transformations can be shown, with corresponding equilibrium hydrogen weight percentages in parentheses, as follows:

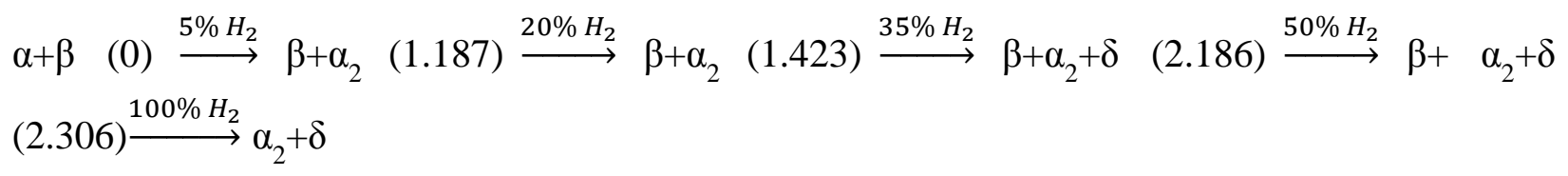

Details of each step of these phase transformations are further examined below.

\subsubsection{Phase changes during heating}

Fig. 6 shows the in-situ XRD results during heating to $550{ }^{\circ} \mathrm{C}$ in flowing pure argon, consisting solely of $\alpha$ and $\beta$ phases throughout the entire heating range from ambient to $550{ }^{\circ} \mathrm{C}$. In Fig. 6, the intensity of $\alpha$ peaks decreased slightly during heating, indicating a small amount of $\alpha$ transformed to $\beta$. The $\beta$ phase peak shifted left toward lower $2 \theta$ values as temperature increased to $436{ }^{\circ} \mathrm{C}$, suggesting there is a lattice expansion of the $\beta$ phase, while there was no obvious shift of the $\alpha$ phase peaks. A similar phenomenon of different lattice expansions in Ti6Al-4V during heating was also reported by J. W. Elmer et al. in synchrotron X-ray experiments [29]. In their work, the thermal expansion coefficient of $\alpha$ was measured as $9.7 \times 10^{-6} /{ }^{\circ} \mathrm{C}$; and 
that of $\beta$ was $9.2 \times 10^{-6} /{ }^{\circ} \mathrm{C}$ below $\sim 450{ }^{\circ} \mathrm{C}$, but rose to $5.8 \times 10^{-5} /{ }^{\circ} \mathrm{C}$ above $\sim 550{ }^{\circ} \mathrm{C}$ [29]. A possible explanation proposed by J. W. Elmer et al. for the rapid $\beta$ lattice expansion in Ti-6Al$4 \mathrm{~V}$ without hydrogen is that the atomic radius of $\mathrm{V}$ is smaller than that of $\mathrm{Ti}$, so the transformation of $\alpha$ to $\beta$ decreased the average $\mathrm{V}$ concentration in the $\beta$ phase and caused an expansion in $\beta$ lattices [29].

\subsubsection{Phase transformation from $\alpha$ phase to $\beta$ phase}

After heating, hydrogen was introduced and the samples were isothermally hydrogenated at varying hydrogen partial pressures. The hydrogenation process can be divided into two steps based on the rate of weight gain at 5\% hydrogen in Fig. 5a: (1) slow and (2) fast absorption. From the in situ XRD results in Fig. 7, the position of $\beta$ peaks was again observed to have shifted to the left at the beginning of hydrogenation, while the positions of peaks for the $\alpha$ phase did not change because the solubility of hydrogen in the $\alpha$ phase is negligible compared with that in $\beta$ [30]. Because the weight ratio of $\beta$ phase to $\alpha$ phase at ambient temperature is approximately 15:85 (estimated from XRD spectra in Fig. 3) and hydrogen atoms diffuse significantly slower in $\mathrm{HCP}-\alpha$ than in the BCC- $\beta$ phase. The rate of hydrogen absorption is thus relatively slow during the first step, where the diffusion path is primarily through the $\alpha$ phase.

Since hydrogen is a $\beta$ stablizer in taitanium, $\alpha$ transformed to $\beta$ as more hydrogen was absorbed. This is shown by the decrease in the intensity of $\alpha$ peaks and the increase in the intensity of $\beta$ peaks in Fig. 7. As a result, the kinetics of hydrogen absorption became faster during the second step. Fig. 7 also shows that peak positions of the newly formed $\beta$ phase, stabilized mainly by hydrogen, are slightly offset from the peak positions of the original $\beta$ phase, which is primarily stabilized by vanadium. The original and newly formed $\beta$ phase were designated as $\beta(\mathrm{V})$ and $\beta(\mathrm{H})$, respectively for clarity. As discussed above, the dissolution of $\mathrm{V}$ in 
$\beta-\mathrm{Ti}$, as a substitutional element, would cause lattice shrinkage due to a smaller atomic radius; while the dissolution of hydrogen, as an interstitial element in $\beta-\mathrm{Ti}$, would cause a lattice expansion. The new $\beta(\mathrm{H})$ phase transformed from $\alpha$ has less vanadium and more hydrogen, and therefore a larger lattice parameter than $\beta(V)$, which shows peaks at lower angles in XRD. In addition, at $550{ }^{\circ} \mathrm{C}$, the slow diffusion rate of metallic alloying elements supports the formation of $\beta(\mathrm{H})$.

\subsubsection{Formation of the $\alpha_{2}$ phase, $\mathrm{Ti}_{3} \mathrm{Al}$}

Fig. 7 shows that all $\alpha$ transformed to $\alpha_{2}$ and $\beta(\mathrm{H})$ after the sample was hydrogenated for approximately 85 minutes. This is an important observation because $\alpha_{2}$ is known to have significant effects on mechanical properties of Ti-6Al-4V [31]. The $\alpha_{2}$ phase is an ordered DO19 structure, and typically precipitates when $\mathrm{Al}$ concentration is higher than 6-7 wt.\% according to the Ti-Al phase diagram [32]. The hydrogenation process may lead to redistribution of Al within the microstructure, forcing it above the threshold value to precipitate $\alpha_{2}$. One explanation is that when $\beta(H)$ was transformed from the $\alpha$ phase, sufficient Al was rejected from the $\beta(H)$ to raise the $\mathrm{Al}$ concentration locally beyond the threshold such that the $\alpha_{2}$ phase would precipitate within the $\alpha$ phase. It is worth mentioning that all $\alpha$ transformed to $\beta(H)$ and $\alpha_{2}$ when equilibrium was reached at $550{ }^{\circ} \mathrm{C}$. The observation of $\alpha_{2}$ in this work is consistent with the literature. Zhang C. et al. reported an observation of $\alpha_{2}$ in hydrogenated Ti-6Al-4V at $650{ }^{\circ} \mathrm{C}$ with more than 0.58 wt. $\%$ hydrogen [18]. Other groups have also reported the formation of $\alpha_{2}$ phase after hydrogenating Ti$6 \mathrm{Al}-4 \mathrm{~V}$ or during the THP process $[33,34]$.

\subsubsection{Formation of $\delta$ hydride phase}

The titanium hydride phase, $\mathrm{FCC}-\delta$, formed when the hydrogen/argon ratio was increased to $35 \%$ hydrogen, as shown in Fig. 8. The absorption process in $35 \% \mathrm{H}_{2}$ can also be divided into 
two steps based on the rate of absorption (Fig. 5a). Initially, the rate of hydrogen absorption was fast due to the rapid diffusion of interstitial hydrogen atoms in the $\beta$ phase. Subsequently, the rate of absorption was slowed as a result of the formation of the $\delta$ hydride phase, which was clearly observed in Fig. 8. According to the binary Ti-H phase diagram [30], titanium hydride can be transformed from both the $\alpha$ and $\beta$ phases. In Fig. 8, during an isothermal hold at $550{ }^{\circ} \mathrm{C}$ the intensity of $\alpha_{2}$ and $\beta(\mathrm{V})$ stayed constant, while the $\beta(\mathrm{H})$ peaks weakened, indicating that the $\delta$ hydride phase was primarily transformed from the hydrogen stabilized $\beta$ phase. It should be noted that this reaction was not rapid, and required approximately 3 hours to reach hydrogen and phase equilibrium at $35 \% \mathrm{H}_{2}$ and $550{ }^{\circ} \mathrm{C}$.

\subsubsection{Microstructure after hydrogenation}

The microstructure of the "as received" Ti-6Al-4V ELI alloy consisted of fine equiaxed $\beta$ grains and $\alpha$ phase, Fig. 4. After hydrogenation, these two phases transformed to ultra-fine $\alpha_{2}$ and $\delta$ phases shown in Fig. 9, but the original $\alpha / \beta$ phase boundaries are still visible in Fig. 9b (white lines). The presence of the original $\alpha / \beta$ phase boundaries is attributed to the fact that the temperature of $550{ }^{\circ} \mathrm{C}$ is too low for $\mathrm{V}$ diffusion to effectively redistribute in titanium, so the original $\beta$ area was still rich in $\mathrm{V}$.

\subsubsection{Phase transformations during isothermal hydrogenation at different temperatures and} hydrogen partial pressures

\subsubsection{Sequence of Phase transformations during hydrogenation}

In addition to the study at $550{ }^{\circ} \mathrm{C}$, phase transformations during hydrogenation at higher and lower temperatures were also studied using similar techniques. From the TGA-DSC curves of isothermal hydrogenation at $650{ }^{\circ} \mathrm{C}$ in Fig. 10a, significant weight gain and a large exothermic 
peak were observed only at $5 \% \mathrm{H}_{2}$, as a result of the phase transformation from $\alpha$ to $\beta$. Unlike isothermal hydrogenation at $550{ }^{\circ} \mathrm{C}$, no $\delta$ hydride phase was observed during isothermal hydrogenation at $650{ }^{\circ} \mathrm{C}$ in up to $100 \% \mathrm{H}_{2}$, as shown in Fig. $10 \mathrm{~b}$. The $\delta$ hydride phase did form, however, during furnace cooling in flowing pure argon. Peaks of $\alpha_{2}$ appeared at $5 \% \mathrm{H}_{2}$. Based on those results, the sequence of the phase transformations with equilibrium hydrogen weight percentage during hydrogenation at $650^{\circ} \mathrm{C}$ is presented as follows:

$$
\alpha+\beta(0) \stackrel{5 \% H_{2}}{\longrightarrow} \alpha+\beta+\alpha_{2}\left(0.674 \text { wt. } \% \text { H) } \stackrel{20 \% H_{2}}{\longrightarrow} \beta+\alpha_{2}(1.039) \stackrel{50 \% H_{2}}{\longrightarrow} \beta+\alpha_{2}(1.325) \stackrel{100 \% H_{2}}{\longrightarrow} \beta+\alpha_{2}\right.
$$

TGA and DSC curves at $750{ }^{\circ} \mathrm{C}$ are shown in Fig. 10c. The kinetic rates of hydrogen aborption were very fast, as evidenced by the equilibiums reached at each hydrogen ratio within a few munites. Most of the $\alpha$ phase transformed to $\beta$ phase in $5 \% \mathrm{H}_{2}$, and the amount of $\alpha$ phase decreased with an increase of hydrogen ratio, as shown in Fig. 10d. However, when the hydrogen ratio was increased from $5 \%$ to $20 \%$, the $\alpha_{2}$ phase was observed during the isothermal hold, as shown in Fig. 10d. Overall, the phase transformations during hydrogenation at $750{ }^{\circ} \mathrm{C}$ followed the sequence (hydrogen wt.\% in parentheses):

$$
\alpha+\beta(0) \stackrel{5 \% H_{2}}{\longrightarrow} \alpha+\beta(0.332) \stackrel{20 \% H_{2}}{\longrightarrow} \alpha+\beta+\alpha_{2}(0.610) \stackrel{50 \% H_{2}}{\longrightarrow} \beta+\alpha_{2}(0.877) \stackrel{100 \% H_{2}}{\longrightarrow} \beta+\alpha_{2}
$$

After isothermal hydrogenation the sample was cooled from $750{ }^{\circ} \mathrm{C}$ in Ar. Compared to the samples that were hydrogenated at $650{ }^{\circ} \mathrm{C}$, no hydride phase formed during cooling from $750{ }^{\circ} \mathrm{C}$, because most of the hydrogen in the material was released during cooling from $750{ }^{\circ} \mathrm{C}$ in flowing Ar.

XRD spectra at $850{ }^{\circ} \mathrm{C}$ are shown in Fig. 10f, showing that most of the $\alpha$ phase transformed to $\beta$ phase upon heating to $850{ }^{\circ} \mathrm{C}$, but was still in the $\alpha+\beta$ two-phase region, since the beta transus temperature is $975^{\circ} \mathrm{C}$ for Ti-6Al-4V (with 0.13 wt.\% O) [31]. When exposed to $5 \% \mathrm{H}_{2}$ at 
$850{ }^{\circ} \mathrm{C}$, the remaining $\alpha$ phase completely transformed to $\beta$, thus monolithic $\beta$ phase was obtained under these conditions. It is worth mentioning that this phase transformation completed very quickly (within 50 seconds), and significant grain growth was observed during hydrogenation. The intensity of some diffraction rings collected by the detector became extremely strong and saturated due to the grain growth, so XRD patterns were not collected at higher hydrogen ratios.

In order to narrow the range of possible locations of the phase boundary that separates the $\beta$ phase field from the $\alpha+\beta$ phase field, isothermal hydrogenation was conducted at $800{ }^{\circ} \mathrm{C}$ as well. Fig. 11 shows that Ti-6Al-4V is in the $\alpha+\beta$ phase region at $800{ }^{\circ} \mathrm{C}$ with hydrogen ratios up to $100 \%$, and $\alpha_{2}$ peaks appeared when the hydrogen ratio increased from $20 \%$ to $50 \%$. The phase transformation sequence with equilibrium $\mathrm{H}$ wt. $\%$ during hydrogenation at $800{ }^{\circ} \mathrm{C}$ was:

$$
\alpha+\beta(0) \stackrel{5 \% H_{2}}{\longrightarrow} \alpha+\beta(0.271) \stackrel{20 \% H_{2}}{\longrightarrow} \alpha+\beta(0.511) \stackrel{50 \% H_{2}}{\longrightarrow} \alpha+\beta+\alpha_{2}(0.790) \stackrel{100 \% H_{2}}{\longrightarrow} \beta+\alpha_{2}
$$

\subsubsection{Microstructure after hydrogenation}

The temperature of hydrogenation has a strong influence on the microstructure. A very fine microstructure with a mixture of $\alpha$ and $\delta$ phases was formed in the specimen with $1.316 \mathrm{wt} . \% \mathrm{H}_{2}$ (38.4 at.\%), hydrogenated at $650{ }^{\circ} \mathrm{C}$, Fig. 12a. The phase transformation associated with the formation of $\alpha$ and $\delta$ phases will be further discussed later in section 3.2. Some remaining $\beta$ grains (dark in Fig. 12a) are present, and the $\alpha_{2}$ phase, which is present given XRD data presented in Fig. 10a, is not readily observable in Fig. 12a.

The sample hydrogenated at $850{ }^{\circ} \mathrm{C}$ (Fig. 12c) shows a very different microstructure with elongated $\alpha$ and $\beta$ grains. The alloy would have been in a single phase $\beta$ region, and all $\alpha$ phase would have transformed to $\beta$ phase when the sample was hydrogenated at $850{ }^{\circ} \mathrm{C}$. However, during cooling in argon, hydrogen was gradually released from the Ti bulk, and as a result, $\alpha$ 
phase precipitated when the hydrogen was not sufficiently high to retain $\beta$ phase at the lower temperature. After this partial dehydrogenation during cooling, the hydrogen concentration decreased to as low as $0.023 \mathrm{wt} . \%(1.06$ at.\%).

According to the XRD results, Fig. 10d, the alloy hydrogenated at $750{ }^{\circ} \mathrm{C}$ in $100 \% \mathrm{H}_{2}$ consisted of $\beta$ and $\alpha_{2}$ phases. The $\alpha_{2}$ phase, as a minor phase at $750{ }^{\circ} \mathrm{C}$, was retained at room temperature with a more equiaxed shape, as shown in Fig. 12b. The elongated $\alpha$ grains were newly formed during cooling due to partial dehydrogenation. As can be seen from the micrographs in Fig. 12, the microstructure is highly dependent on hydrogen content and thermal history.

\subsubsection{Partial Pseudo-binary $\left(\right.$ Ti-6Al-4V)-xH phase diagram above $450^{\circ} \mathrm{C}$}

Based on the correlation of the hydrogen contents in samples exposed to various partial hydrogen pressure and temperatures, measured using TGA-DSC, with the phase identifications using in situ XRD at corresponding conditions, a partial pseudo-binary phase diagram for the (Ti-6Al-4V)-xH system is plotted in Fig. 13. The filled data points in Fig. 13 are those determined using both TGA-DSC and in situ XRD with hydrogen partial pressure varying from 0.05 to $0.5 \mathrm{~atm}$. As mentioned earlier, the TGA-DSC unit that was used in this work was not equipped to be operated under $100 \%$ hydrogen.

However, in the in situ XRD experiments, phase compositions were collected for hydrogen partial pressure from $0.05 \mathrm{~atm}$ to $1.0 \mathrm{~atm}$. In order to determine corresponding hydrogen content versus partial pressure and temperature data, the general form of Sievert's Law $\left(C_{H}=K P_{H}^{n}\right)$ was used to model the relationships between hydrogen content, partial pressure of hydrogen, and temperature [35]. In this equation, $\mathrm{C}_{\mathrm{H}}$ is the hydrogen content (at. \%), $\mathrm{P}_{\mathrm{H}}$ is hydrogen partial 
pressure (atm) and $\mathrm{K}$ is a constant at a certain temperature. This equation was able to fit experimental data very well at all temperatures except 500 and $550{ }^{\circ} \mathrm{C}$, where the formation of the titanium hydride phase interrupted the functions. Using this model, equilibrium hydrogen contents at $1.0 \mathrm{~atm}$ were calculated and listed in Table 1 along with values of $\mathrm{A}, \mathrm{n}$ and $\mathrm{R}^{2}$. The values of $\mathrm{n}$ from the data fitting are in the range of $0.0364-0.4157$, indicating the deviation of the actual data from the assumption of an ideal solution of the model. The calculated hydrogen contents at $1.0 \mathrm{~atm}$ are shown in Fig. 13. Combined with the in situ XRD data, the partial pseudo-binary phase diagram of (Ti-6Al-4V)-xH is more complete defining the phase boundaries as functions of both pressure and temperature.

\subsection{Determining (Ti-6Al-4V)-xH phase diagram below $450^{\circ} \mathrm{C}$}

As discussed above, during isothermal hydrogenation at $650{ }^{\circ} \mathrm{C}$, only $\beta$ and $\alpha_{2}$ phases were present; however $\delta$ hydride and $\alpha$ were observed in samples that were cooled in $\mathrm{Ar}$ from $650{ }^{\circ} \mathrm{C}$, which indicates there might be a phase transformation of $\beta \leftrightarrow \alpha+\delta$, and there could be a four phase region $\left(\alpha+\beta+\alpha_{2}+\delta\right)$ in the phase diagram in the low temperatrue range. To date, however, there are no reports of such phase transformations and/or a four-phase region, and of the earlier work cited in the introduction, only the phase diagram proposed by A. A. Ilyn alluded to a low temperature phase transformation in this system at approximately $200{ }^{\circ} \mathrm{C}$. It is, however, important that these possible transformations are investigated to gain a more accurate and complete understanding of the microstructure of Ti-6Al-4V after heat treatments in hydrogen.

The study of phase transformation at low temperatures is significantly more difficult than that at higher temperatures, such as above $450{ }^{\circ} \mathrm{C}$, for reasons of slow long-range diffusion kinetics. For example, in the isothermal hydrogenation experiments, an equilibrium hydrogen content was reached within 600 minutes at $500{ }^{\circ} \mathrm{C}$, while it would require $\sim 8200$ minutes $(137$ 
hours) to reach equilibrium at $450{ }^{\circ} \mathrm{C}$. Therefore, a different methodology had to be used to investigate the phase transformations below $450{ }^{\circ} \mathrm{C}$.

As mentioned earlier, the hydrogen content does not change in flowing argon at temperatures below $450{ }^{\circ} \mathrm{C}$. Thus, at low temperatures, the phase transformations in Ti-6Al-4V with known constant hydrogen contents can be studied during heating and cooling without losing hydrogen in flowing Ar during either TGA-DSC or in situ X-ray experiments, exploiting the benefits of slow hydrogen diffusion kinetics. To summarize the general approach, at temperature above $450{ }^{\circ} \mathrm{C}$, the phase transformations were studied at a constant temperature with varying hydrogen content, while at $\mathrm{T}$ below $450{ }^{\circ} \mathrm{C}$, they were observed at a constant hydrogen content with varying temperature.

\subsubsection{Eutectoid transforamtion $\beta \leftrightarrow \alpha+\delta$}

In order to determine the temperature of phase transition at a given hydrogen content, the DSC technique was used to determine the temperature of the transition during continuous heating of a sample with a known hydrogen content. To prepare such samples, thin Ti64 ELI discs were first hydrogenated at different temperatures and partial pressures of hydrogen as described in the experimental section. The samples with different hydrogen content were then heated in the TGA-DSC unit. Because the hydrogen content does not change during heating at temperatures below $450{ }^{\circ} \mathrm{C}$, the DSC peaks indicate phase transitions at the specific hydrogen contents. The specific hydrogen content was determined by heating the sample to a significantly higher temperature to allow the hydrogen to completely release and measuring the weight loss.

The TGA-DSC curves collected during heating of Ti-6Al-4V with 1.160 wt.\% (35.4 at.\%) hydrogen are shown in Fig. 14. It can be seen that there are two significant DSC peaks. The first 
small endothermic peak in the lower temperature range (near $200{ }^{\circ} \mathrm{C}$ ) signals a phase transformation at this temperature. Note, at this point there was no weight loss observed, demonstrating that hydrogen was constant in the system until this temperature. Further, this peak was not present during the cooling of this same specimen after it was fully dehydrogenated at higher temperatures, suggesting that this phase transformation is associated with the presence of hydrogen in the Ti-6Al-4V alloy. The second large endothermic peak at higher temperature, however, corresponds to the weight loss (solid red) curve, which started at approximately $461{ }^{\circ} \mathrm{C}$, and is clearly the result of dehydrogenation.

In order to confirm the phase transition as indicated by DSC peaks described above, in situ synchrotron XRD was again used to measure phase changes by heating a pre-hydrogenated sample to $750{ }^{\circ} \mathrm{C}$ using a $10^{\circ} \mathrm{C} / \mathrm{min}$ heating rate, an isothermal hold at $750{ }^{\circ} \mathrm{C}$ for 30 minutes, and then furnace cool, all in flowing argon. The resulting XRD spectra are shown in Fig. 15, and exhibit a transformation from $\alpha+\delta \leftrightarrow \beta$ phase (i.e. a eutectoid transformation) at approximately $200{ }^{\circ} \mathrm{C}$ during heating. Combined with the endothermic peak of the DSC curve, this is strong evidence of the existence of a eutectoid phase transformation (i.e. $\beta \leftrightarrow \alpha$ and $\delta$ ) at approximately $200{ }^{\circ} \mathrm{C}$ in the (Ti-6Al-4V)-xH system. It is noted that the large right shifts of $\alpha, \alpha_{2}$ and $\beta$ peaks between $450{ }^{\circ} \mathrm{C}$ and $750{ }^{\circ} \mathrm{C}$ during heating were caused by the release of hydrogen atoms from the given lattices, while the right shifts of $\alpha$ and $\beta$ peaks during cooling after dehydrogenation were due to thermal shrinkage. The starting temperature of this eutectoid transformation was measured as the onset temperature of the endothermic peak before dehydrogenation on the DSC curve. The onset temperature of a thermal peak can be typically determined by two methods: the extrapolation method and the first detectable deviation method [36]. In the extrapolation method, the onset temperature is taken as the intersection of the extrapolated tangent line at the inflection 
point of the leading edge of the peak and the extrapolation of the baseline. This method is used in ASTM standard E967 to extract the onset temperature to establish the melting points of pure metals. In the other method, the onset temperature is obtained as the first detectable deviation from the baseline. In the present study, the extrapolation method was employed to determine the onset temperature on DSC curves, which is shown on the blue line in Fig 14.

Fig. 14 also illustrates the influence of heating/cooling rate on the onset temperature of the eutectoid transformation. The onset temperature during heating at $10^{\circ} \mathrm{C} / \mathrm{min}$ is slightly higher than that at $5^{\circ} \mathrm{C} / \mathrm{min}$. Although the cooling rate set in the control program for the TGA-DSC was 5 and $10^{\circ} \mathrm{C} / \mathrm{min}$, the actual cooling rates were very similar to one another and lower than the set rates $\left(1-2^{\circ} \mathrm{C} / \mathrm{min}\right)$, because the specimens were furnace-cooled in the TGA-DSC and forced cooling could not be used. The actual cooling rates were limited by the $\Delta \mathrm{T}$ between the furnace temperature and ambient.

Fig. 14 also shows an endothermic peak at $195{ }^{\circ} \mathrm{C}$. It is similar to those reported by the current authors on dehydrogenation of CP-Ti with 40.7 at.\% $\mathrm{H}$ [26], which is associated with the eutecoid tranformation $\beta \leftrightarrow \alpha+\delta$ according to the well stablished Ti-H phase diagram [30]. The eutectoid temperature and hydrogen composition in the Ti-H system were determined by I. O. Bashkin in 1992 [37]. In that study, high purity Ti specimens were hydrogenated to have 0.71$1.12 \mathrm{wt} . \% \mathrm{H}$, and then calorimetric measurements were conducted in a DSC instrument between $47-477{ }^{\circ} \mathrm{C}$ to determine phase boundaries. The onset temperatures of thermal peaks on DSC curves were also determined by the extrapolation method. In the present work a similar method was used to determine the eutectoid transformation in the (Ti-6Al-4V)-xH system. 


\subsubsection{Determining the temperature of eutectoid transformation versus hydrogen content}

The last section described how the temperature of the eutectoid transformation was determined for a given hydrogen content. In this section, the onset temperature of the eutectoid transformation was obtained from the peak on the DSC curves during heating at $10{ }^{\circ} \mathrm{C} / \mathrm{min}$ through a range of hydrogen concentrations. The DSC curves of Ti-6Al-4V with different hydrogen contents during heating are shown in Fig. 16. Endothermic peaks were examined in the hydrogen content range from 17.3 to 45.3 at.\%. Fig. 16 shows that the hydrogen content had a strong effect on the onset temperature and on the total area under the peaks (thermal energy absorbed). The area under the peak and the onset temperature were observed to increase as hydrogen content approached 37.5 at.\%. Therefore, the eutectoid point was determined to be (37.5 at. $\left.\% \mathrm{H}, 211^{\circ} \mathrm{C}\right)$.

\subsection{Proposed pseudo-binary (Ti-6Al-4V)-xH phase diagram}

A pseudo-binary (Ti-6Al-4V)-xH phase diagram is proposed in Fig. 17, by incorporating the eutectoid phase transformation below $450{ }^{\circ} \mathrm{C}$ into the phase boundary data presented in Fig. 13 . Fig.17 shows that the $\beta$ transus temperature decreases with increasing hydrogen content up to approximately 10 at.\% hydrogen, which is consistent with previous research [11, 17, 22]. For Ti6Al-4V (0.13 wt. \% O) without hydrogen, the beta transus temperature is $975^{\circ} \mathrm{C}[31]$, while only the $\beta$ phase was observed in the present study at $850{ }^{\circ} \mathrm{C}$ with 9.0 at. $\% \mathrm{H}_{2}$, having been exposed to $5 \% \mathrm{H}_{2}$. Thus, at 9.0 at. $\% \mathrm{H}_{2}$ the $\beta$ transus must be below $850{ }^{\circ} \mathrm{C}$. As shown in Fig. 1, W. R. Kerr

and J. I. Qazi et al. determined the $\beta$ transus temperature to be at an approximately constant value of $820^{\circ} \mathrm{C}$ for hydrogen content higher than 20 at. $\%[12,22]$, which is in general agreement with the present work. 
A three-phase-region of $\alpha+\beta+\alpha_{2}$ and a two-phase-region of $\beta+\alpha_{2}$ were observed in the present work, and the $\alpha_{2}$ phase was observed as an equilibrium phase in the (Ti-6Al-4V)-xH system. Oxygen has been proven to be a strong promoter for forming $\alpha_{2}$ [38-40]. M. Yan et al. recently reported the observation of $\alpha_{2}$ precipitation in sintered Ti-6Al-4V-0.49O and the absence of $\alpha_{2}$ precipitation in sintered Ti-6Al-4V-0.25O [41]. In the present study, the $\mathrm{O}$ content in the starting material was $0.13 \mathrm{wt} . \%$. The oxygen contents in Ti-6Al-4V isothermally hydrogenated at $900{ }^{\circ} \mathrm{C}$ and $850{ }^{\circ} \mathrm{C}$, the two highest hydrogenation temperature in the present study, were measured at 0.22 wt. $\%$ and 0.18 wt. $\%$, which excludes the possibility of forming $\alpha_{2}$ due to the oxygen uptake during hydrogenation in the present study. Therefore, hydrogen is believed to account for the transformation of $\alpha \rightarrow \alpha_{2}$. The $\alpha_{2}$ phase precipitated during hydrogenation at or below $750{ }^{\circ} \mathrm{C}$, and a higher hydrogen ratio was required to form $\alpha_{2}$ at higher temperatures. No $\alpha_{2}$ phase precipitated at $850{ }^{\circ} \mathrm{C}$, even at $100 \%$ hydrogen in this study, since $\alpha_{2}$ may not be thermodynamically stable at elevated temperatures, or the hydrogen partial pressure employed in this study was not sufficiently high at this temperature to force precipitation. The precipitation of $\alpha_{2}$ inside of $\alpha$ grains has also been observed to occur when Ti-6Al-4V is aged in the temperature range of 500$600{ }^{\circ} \mathrm{C}[42,43]$. The dehydrogenation experiments in flowing argon described earlier showed that $\alpha_{2}$, which had formed during isothermal hydrogenation, started to dissolve at elevated temperature $\left(\sim 700^{\circ} \mathrm{C}\right)$.

In the present work, using TGA-DSC combined with in situ synchrotron XRD, eutectoid reactions were observed at low temperature and a unique eutectoid temperature was determined as $211^{\circ} \mathrm{C}$, a value that is close to that of the Ti-H system. The DSC-TGA and in situ synchrotron X-ray experiments reported here benefit from examining phase transitions directly in real time. Previous research has indicated that titanium hydride formed if hydrogen content exceeds $\sim 10-15$ 
at. $\%$, or $\sim 15-20$ at. $\%$ at elevated temperature $\left(500-800{ }^{\circ} \mathrm{C}\right)[11,22]$, however, the phase diagram in Fig. 17 shows that titanium hydride only forms below $211^{\circ} \mathrm{C}$ if hydrogen content is in the range of 15-47 at.\%. A possible explanation of this disagreement might be that the hydride phase formed as the samples moved through the lower temperature phase region, despite the fast cooling process (i.e. quenching) in the reported experiments. In addition, no single-phase region of $\delta$ hydride was observed in this research, as opposed to that reported by C. C Shen et al. [24], which is possibly due to the relatively low hydrogen pressure $(<=1 \mathrm{~atm})$. It may be possible that a single phase $\delta$ region exists at higher hydrogen compositions not investigated in this study, but it is also possible that such a region does not exist in near equilibrium conditions.

In addition, the partial phase diagram as determined in this work includes results from varying hydrogen pressure. As discussed in the introduction, pressure is an absolutely necessary factor for describing an equilibrium metal-hydrogen phase diagram. At a fixed temperature, the equilibrium hydrogen content and phases are solely determined by the partial pressure of hydrogen in the atmosphere. Finally, the results reported here were not an attempt to establish a complete phase diagram, but rather, were intended to examine the portions of the phase diagram that pertain directly to compositions and temperatures applicable to the heat treatment or sintering of Ti-6Al-4V in a hydrogen atmosphere.

\section{Conclusions}

A partial pseudo-binary phase diagram of (Ti-6Al-4V)-xH, in the temperature range of 100$900{ }^{\circ} \mathrm{C}$ and $0-60$ at.\% hydrogen, was developed in this paper by investigating hydrogenation/dehydrogenation of the alloy through the use of TGA-DSC and high energy synchrotron X-ray diffraction. 
(1) The eutectoid phase transformation $\beta \leftrightarrow \alpha+\delta$ was determined to be in the hydrogen range of 17.3-45.3 at.\%, and the eutectoid point is 37.5 at. $\%$ at $211{ }^{\circ} \mathrm{C}$. A four phase region of $\alpha+\beta+\alpha_{2}+\delta$ is present below this point in the phase diagram.

(2) A two-phase $\beta+\alpha_{2}$ region is present above the eutectoid point.

(3) The $\alpha_{2}$ phase was observed to form at compositions greater than approximately 22 at. $\%$ hydrogen, but was not evident after dehydrogenation at $750{ }^{\circ} \mathrm{C}$.

(4) The $\delta$ hyride phase can be produced in (Ti-6Al-4V)-xH either as a eutectoid transformed product or as primary $\delta$ phase transformed from the $\beta$ pahse.

(5) The $\beta$ transus temperature was determined to be between $800{ }^{\circ} \mathrm{C}$ and $850{ }^{\circ} \mathrm{C}$ in the hydrogen concentration range of 9.0-19.4 at.\%.

This reported partial phase diagram is intended to serve as a guide for controlling phase transformations and microstructures in THP, HSPT or any process for Ti-6Al-4V involving hydrogen within stated ranges by varying temperature and hydrogen pressure.

\section{Acknowledgement}

The authors acknowledge funding support by U.S. Department of Energy, Innovative Manufacturing Initiative (DEEE0005761), through the Advanced Manufacturing Office and the Office of Energy Efficiency and Renewable Energy. Use of the Advanced Photon Source, an Office of Science User Facility operated for the U.S. Department of Energy (DOE) Office of Science by Argonne National Laboratory, was supported by the U.S. DOE under Contract No. DE-AC02-06CH11357. The first author acknowledges the valuable assistance of Ms. Xiangyi Luo, Mr. Chun Yu and Mr. Rick Spence for synchrotron X-ray experiments at Argonne National 
Lab, and helpful discussions with Dr. Yang Xia and Mr. Chengshang Zhou at the University of

Utah.

\section{References}

[1] Lenning GA, Craighead CM, Jaffee RI. Trans AIME 1954;200:367.

[2] Jaffee RI, Lenning GA, Craighead CM. Trans AIME 1956;206:907.

[3] Beevers CJ, Warren MR, Edmonds DV. J Less Common Met 1968;14:387.

[4] Beevers CJ, Edmonds DV. Trans AIME 1969;245:2391.

[5] Gerard DA, Koss DA. Scripta Metall 1985;19:1521.

[6] ASTM B817-08, Standard Specification for Powder Metallurgy (P/M) Titanium Alloy Structural Components, 2008.

[7] ASTM B348-10, Standard Specification for Titanium and Titanium Alloy Bars and Billets, 2010.

[8] McQuillan AD. Proc Roy Soc A 1950;204:309.

[9] McCracken CG, Motchenbacher C, Barbis DP. Int J Powder Metall 2010;46:19.

[10] Zwicker U, Schleicher HW. U.S. Patent No. 2892742 A, 1959.

[11] Kerr WR, Smith PR, Rosenblum ME, Gurney FJ, Mahajan YR, Bidwell LR. Hydrogen as an Alloying Element in Titanium (Hydrovac). Titanium '80, Science and Technology, Proceedings of the 4th International Conference on Titanium., vol. 4. Kyoto, Jpn: Metall Soc of AIME, 1980. p.2477.

[12] Kerr WR. Metall Mater Trans A 1985;16:1077.

[13] Kao WH, Eylon D, Yolton CF, Froes FH. Effect of Temporary Alloying by Hydrogen (Hydrovac) on the Vacuum Hot Pressing and Microstructure of Titanium Alloy Powder Compacts. 1981 National Powder Metallurgy Conference Proceedings., vol. 37. Philadelphia, PA, USA: Met Powder Ind Fed, 1982. p.289.

[14] Smickley RJ, Dardi LE. U.S. Patent No. 4,505,764, 1985.

[15] Kohn DH, Ducheyne P. J Mater Sci 1991;26:534.

[16] Gong B, Niinomi M, Kobayashi T, Ohyabu Y. J Jpn Inst Light Met 1992;42:638.

[17] Ilyn AA, Kolachev BA, Mamonov AM. Phase and Structure Transformations in Titanium Alloys under Thermohydrogenous Treatment. Titanium'92 Science and Technology. San Diego, 1992. p.941.

[18] Zhang C, Bian W, Lai Z, Gong B. Acta Metall Sin A 1992;5A:362.

[19] Yoshimura H, Kimura K, Hayashi M, Ishii M, Hanamura T, Takamura J. Mater Trans, JIM 1994;35:266.

[20] Fang TY, Wang WH. Mater Chem Phys 1998;56:35.

[21] Froes FH, Senkov ON, Qazi JI. Enhanced Performance near Net Shape Titanium Alloys by Thermohydrogen Processing. Ft. Belvoir: Defense Technical Information Center, 2001.

[22] Qazi JI, Senkov ON, Rahim J, Genc A, Froes FH. Metall Mater Trans A 2001;32:2453.

[23] Froes FH, Senkov ON, Qazi JI. Int Mater Rev 2004;49:227.

[24] Shen CC, Perng TP. Acta Mater 2007;55:1053.

[25] Fang ZZ, Sun P, Wang H. Adv Eng Mater 2012;14:383.

[26] Sun P, Fang ZZ, Koopman M. Adv Eng Mater 2013;10:1007. 
[27] Flanagan TB, Luo W. Determination of Phase Diagrams for Hydrogen-Containing Systems. In: Zhao JC, editor. Methods for Phase Diagram Determination. Elsevier Science, 2011. [28] Jiménez C, Garcia-Moreno F, Pfretzschner B, Klaus M, Wollgarten M, Zizak I, Schumacher G, Tovar M, Banhart J. Acta Mater 2011;59:6318.

[29] Elmer JW, Palmer TA, Babu SS, Specht ED. Mater Sci Eng A 2005;391:104.

[30] Manchester FD, San-Martin A. Hydrogen-Titanium. In: Manchester FD, editor. Phase Diagrams of Binary Hydrogen Alloys. Materials Park, OH: ASM International, 2000.

[31] Lütjering G, Williams JC. Titanium: Springer, 2003.

[32] Baker H. Alloy Phase Diagram. Materials Park, Ohio: ASM International 1992.

[33] Shen CC, Yu CY, Perng TP. Acta Mater 2009;57:868.

[34] Ivanov MB, Manokhin SS, Kolobov YR, Nechayenko DA. Mater Phy Mech 2010;10:62.

[35] Sieverts A. Z Metallkd 1929;21:37.

[36] Boettinger WJ, Kattner UR, Moon K-W, Perepezko JH. Dta and Heat-Flux Dsc Measurements of Alloy Melting and Freezing. In: Zhao JC, editor. Methods for Phase Diagram Determination. Elsevier Science, 2011.

[37] Bashkin IO, Gurov AF, Malyshev VY, Ponyatovskii EG. Soviet Phy Solid State 1992;34:674.

[38] Crossley FA. Trans AIME 1969;245:1963.

[39] Lim JY, McMahon CJ, Pope DP, Jr., Williams JC. Metall Trans A 1976;7:139.

[40] Boyer RR, Spurr WF. Metall Trans A 1978;9:1443.

[41] Yan M, Dargusch MS, Ebel T, Qian M. Acta Mater 2014;68:196.

[42] Welsch G, Lütjering G, Gazioglu K, Bunk W. Metall Trans A 1977;8:169.

[43] Lee DG, Lee S, Lee CS. Mater Sci Eng A 2004;366:25.

\section{Figure and Table Captions}

Fig. 1. Previous (Ti-6Al-4V)-xH phase diagrams published by W. R. Kerr et al. in 1980 [11], A. A. Ilyn et al. in 1992 [17], J. I. Qazi et al. in 2001[22] and C. C. Shen et al. in 2007 [24].

Fig. 2. Schematic diagram of the furnace and $\mathrm{x}$-ray beam for the in situ synchrotron XRD experiments.

Fig. 3. Example of a 1-D X-ray diffraction pattern of starting materials showing the presence of only the $\alpha$ and $\beta$ phases.

Fig. 4. Microstructure of starting material, wrought Ti-6Al-4V ELI, showing equiaxed grains of $\beta$ phase (lighter gray) in an $\alpha$ matrix.

Fig. 5. Isothermal hydrogenation at $550^{\circ} \mathrm{C}$ in (a) TGA-DSC curves of hydrogenating Ti-6Al-4V at $550{ }^{\circ} \mathrm{C}$, showing weight gains for hydrogen ratios from $0 \%$ to $20 \%$ and (b) synchrotron X-ray spectra under the same conditions.

Fig. 6. In situ synchrotron $\mathrm{X}$-ray spectrum of heating to $550{ }^{\circ} \mathrm{C}$ in flowing pure argon. The $\beta$ phase peaks shifted left toward lower $2 \theta$ values. 
Fig. 7. In situ synchrotron X-ray spectra of Ti-6Al-4V during isothermal hydrogenation in $5 \% \mathrm{H}_{2}$ at $550{ }^{\circ} \mathrm{C}$. "New" $\beta$ phase, $\beta(\mathrm{H})$, was observed to form as a result of phase stabilization by hydrogen.

Fig. 8. In situ synchrotron X-ray spectra of formation of titanium hydride during isothermal hydrogenation at $550{ }^{\circ} \mathrm{C}$ in $35 \%$ hydrogen.

Fig. 9. Microstructure at two magnifications after hydrogenation at $550{ }^{\circ} \mathrm{C}$ in $100 \% \mathrm{H}_{2}$, and cooled to ambient conditions in Ar. Retained hydrogen in this sample was 1.938 wt.\%. The original $\alpha / \beta$ phase boundaries in the starting Ti-6Al-4V are still visible, (marked with white lines). (SEM)

Fig. 10. TGA-DSC and in situ XRD results for Ti-6Al-4V during isothermal hydrogenation at $650{ }^{\circ} \mathrm{C}$ (a and b), $750{ }^{\circ} \mathrm{C}$ (c and d) and $850{ }^{\circ} \mathrm{C}$ (e and f).

Fig. 11. XRD results of Ti-6Al-4V isothermally hydrogenated at $800{ }^{\circ} \mathrm{C}$, (a) showing $\alpha$ and $\beta$ peaks at ambient temperature and a range of hydrogen partial pressures at $800{ }^{\circ} \mathrm{C}$, and (b) showing $\alpha_{2}$ peaks with expanded axes.

Fig. 12. Microstructures after being hydrogenated in $100 \% \mathrm{H}_{2}$ at various temperatures: (a) $650{ }^{\circ} \mathrm{C}$, (c) $750{ }^{\circ} \mathrm{C}$ and (d) $850{ }^{\circ} \mathrm{C}$ and cooled in Ar.

Fig. 13. Partial phase diagram of (Ti-6Al-4V)-xH. Only P-C-T information (i.e. DSC-TGA data) was experimentally collected or mathematically extrapolated for the hollow data points, while for filled data points, in addition to P-C-T data, equilibrium phases were determined from in situ $\mathrm{X}$-ray data.

Fig. 14. Dehydrogenation data from TGA-DSC of Ti-6Al-4V-H in flowing argon. The Ti-6Al$4 \mathrm{~V}-\mathrm{H}$ specimen was heated to $400{ }^{\circ} \mathrm{C}$ at a rate of $10{ }^{\circ} \mathrm{C} / \mathrm{min}$, and then cooled to $60^{\circ} \mathrm{C}$ at the same rate. It was then heated to $400{ }^{\circ} \mathrm{C}$ again at a rate of $5^{\circ} \mathrm{C} / \mathrm{min}$, and then cooled to $60^{\circ} \mathrm{C}$ at $5{ }^{\circ} \mathrm{C} / \mathrm{min}$. Finally, the sample was heated to $900{ }^{\circ} \mathrm{C}$ at a rate of $10{ }^{\circ} \mathrm{C} / \mathrm{min}$ for full dehydrogenation, and then cooled to room temperature at a rate of $10^{\circ} \mathrm{C} / \mathrm{min}$. Endothermic and exothermic peaks are shown during heating and cooling before dehydrogenation.

Fig. 15. Synchrotron X-ray spectra of dehydrogenation of Ti-6Al-4V-H in flowing argon. The eutectoid transformation $\beta \leftrightarrow \alpha+\delta$ was observed during heating near $200{ }^{\circ} \mathrm{C}$.

Fig. 16. DSC curves of Ti-6Al-4V with different hydrogen concentrations during heating. The onset temperature of the endothermic peak varied with the hydrogen content in Ti-6Al-4V. The onset temperature is determined by drawing tangent lines in advance of the thermal peaks, as shown in the sample with 37.5 at.\% hydrogen.

Fig. 17. Proposed partial pseudo-binary (Ti-6Al-4V)-xH phase diagram. Dashed lines delineate phase boundaries that are approximate, and not verified by experimental data.

Table 1. Calculated hydrogen content in Ti-6Al-4V at a hydrogen partial pressure of 1.0 atm $\left(100 \% \mathrm{H}_{2}\right)$. 


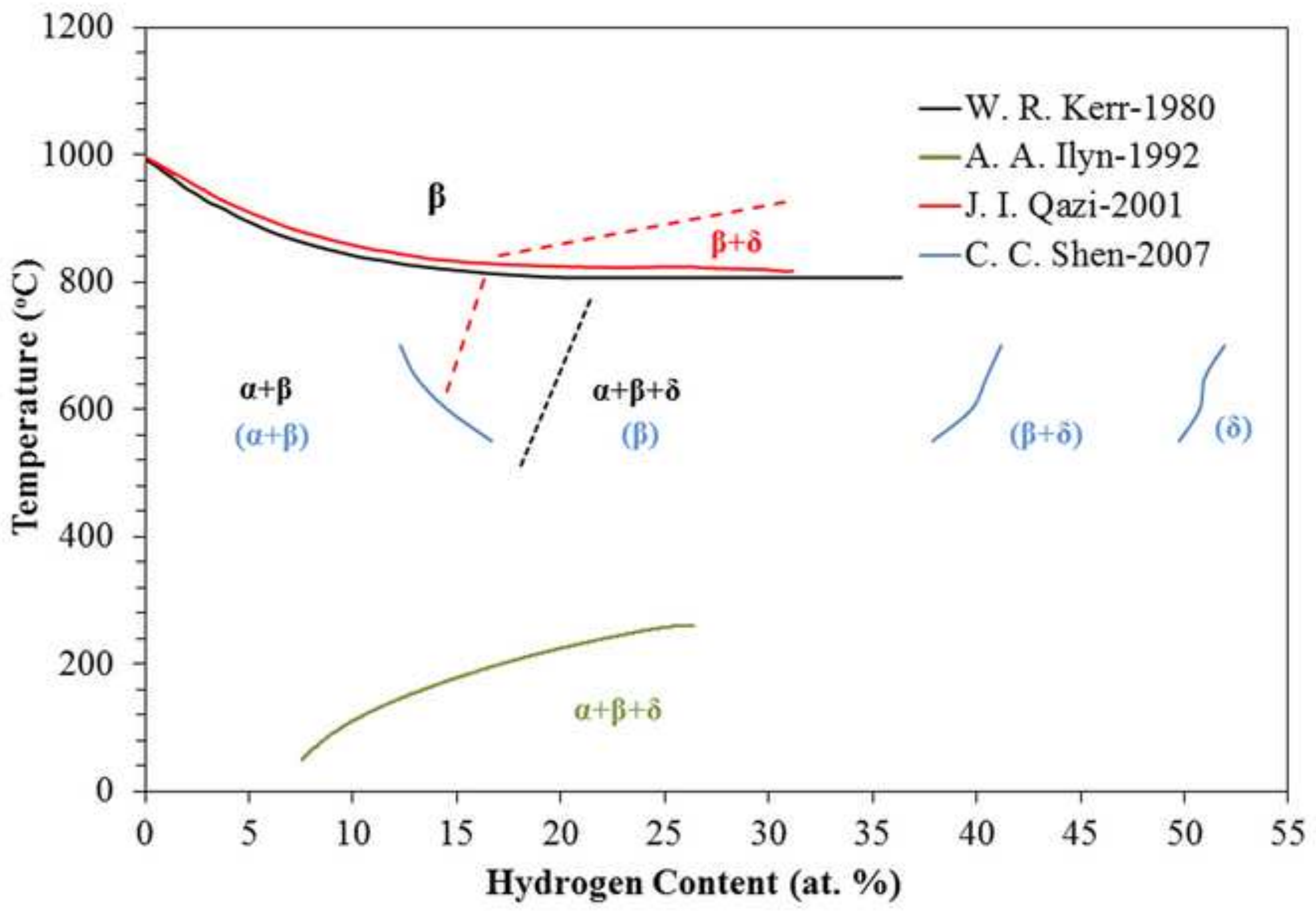




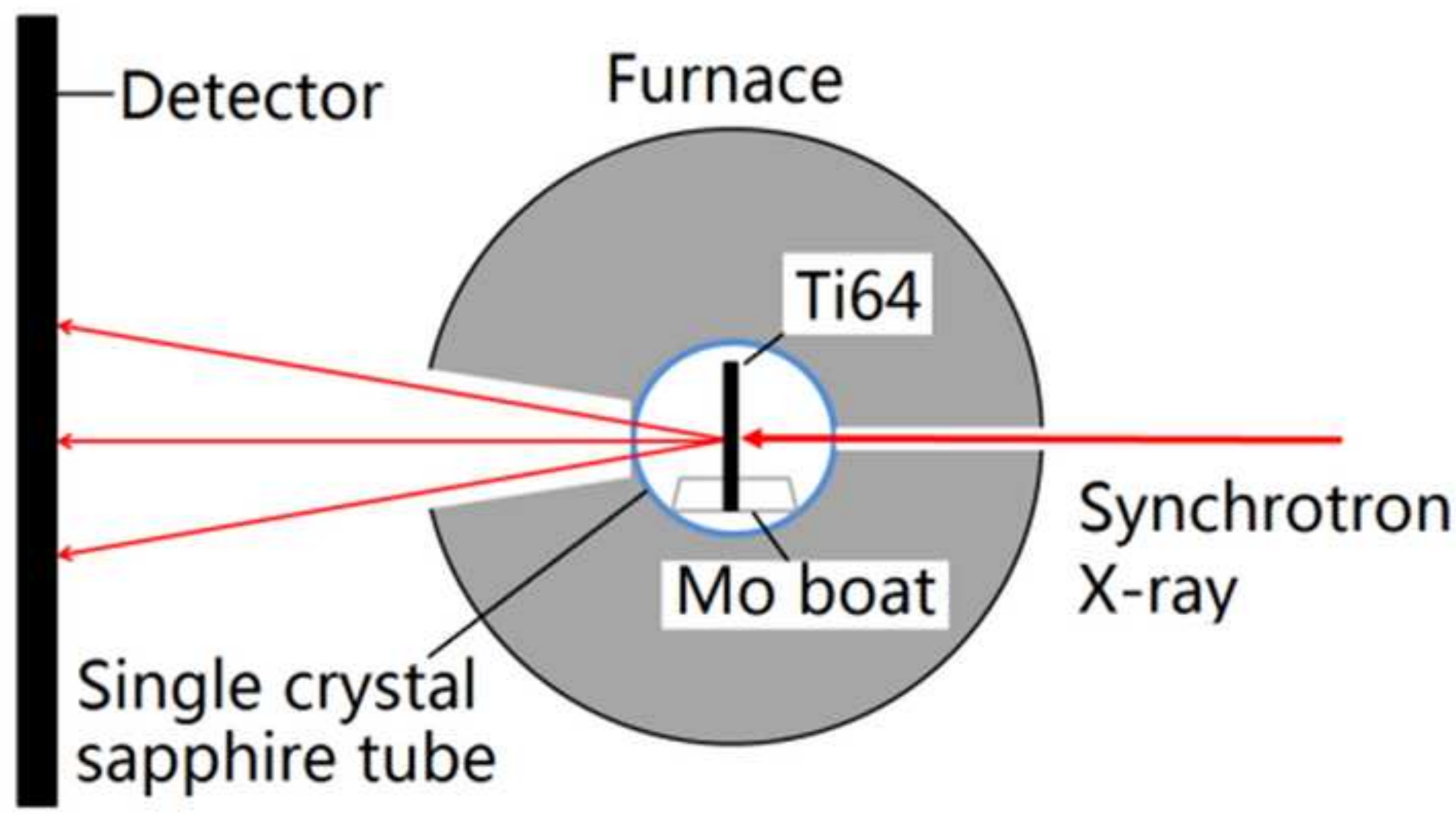




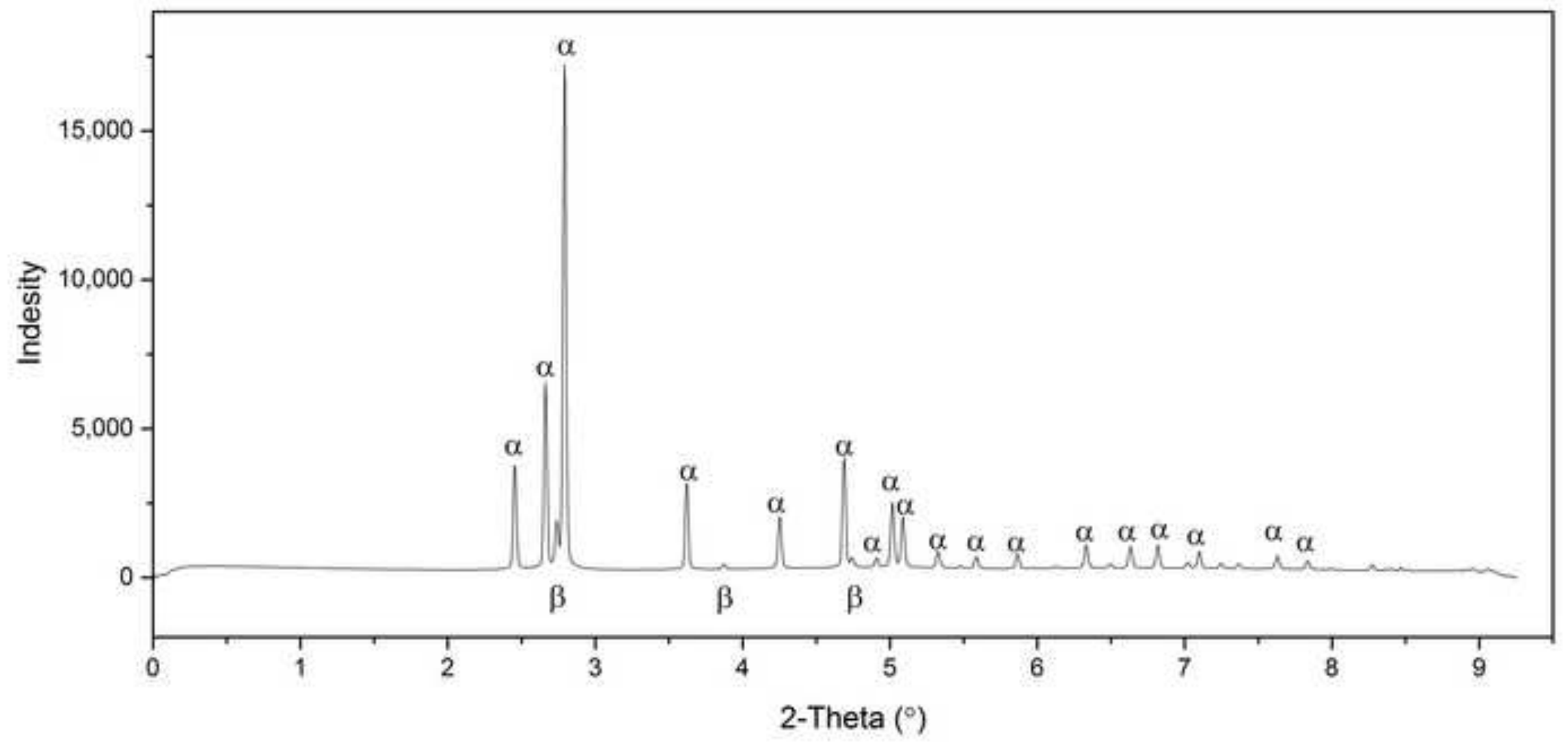


0

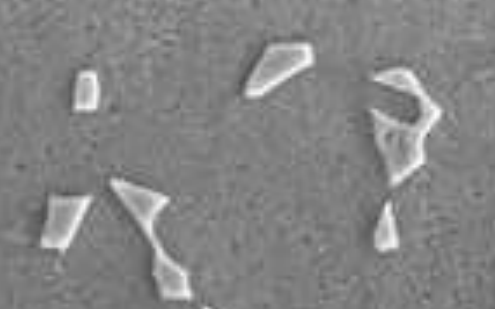

Is

8

b a

10

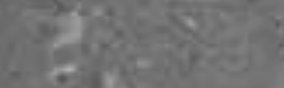

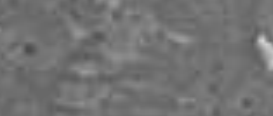

sisid $x^{9}$

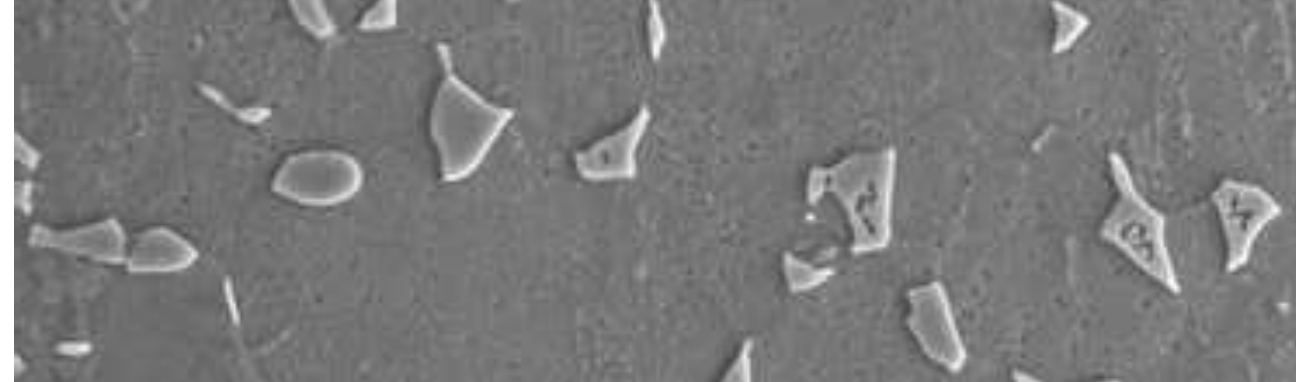

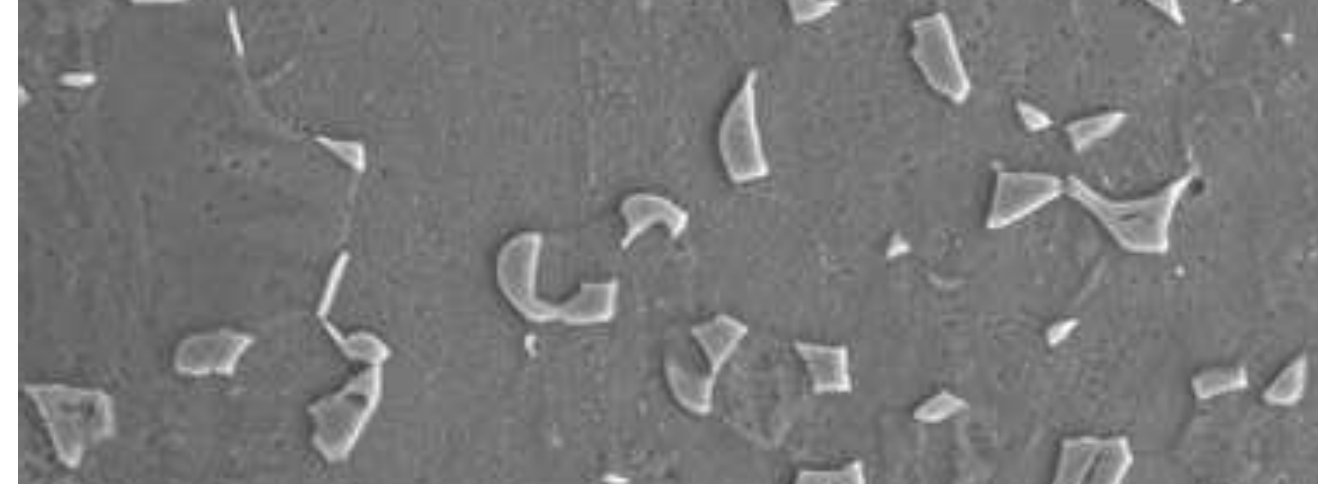

9
-7 वाय
37 is<smiles>[AsH2]</smiles>

$14 \sqrt{3}$

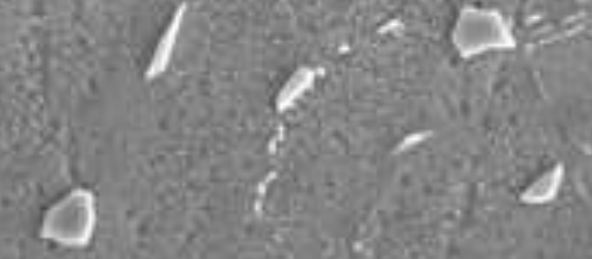

e

4

cos 8

$\theta=\sqrt{7}$

$y+5,8$

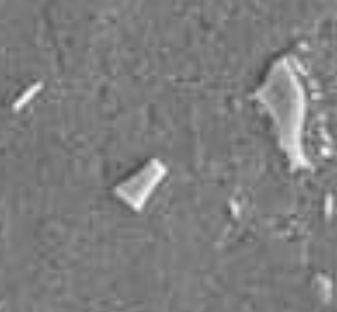

$9=0$

$\left\{\int^{1} \mathrm{~s} \quad 5 \mu \mathrm{m}\right.$ 

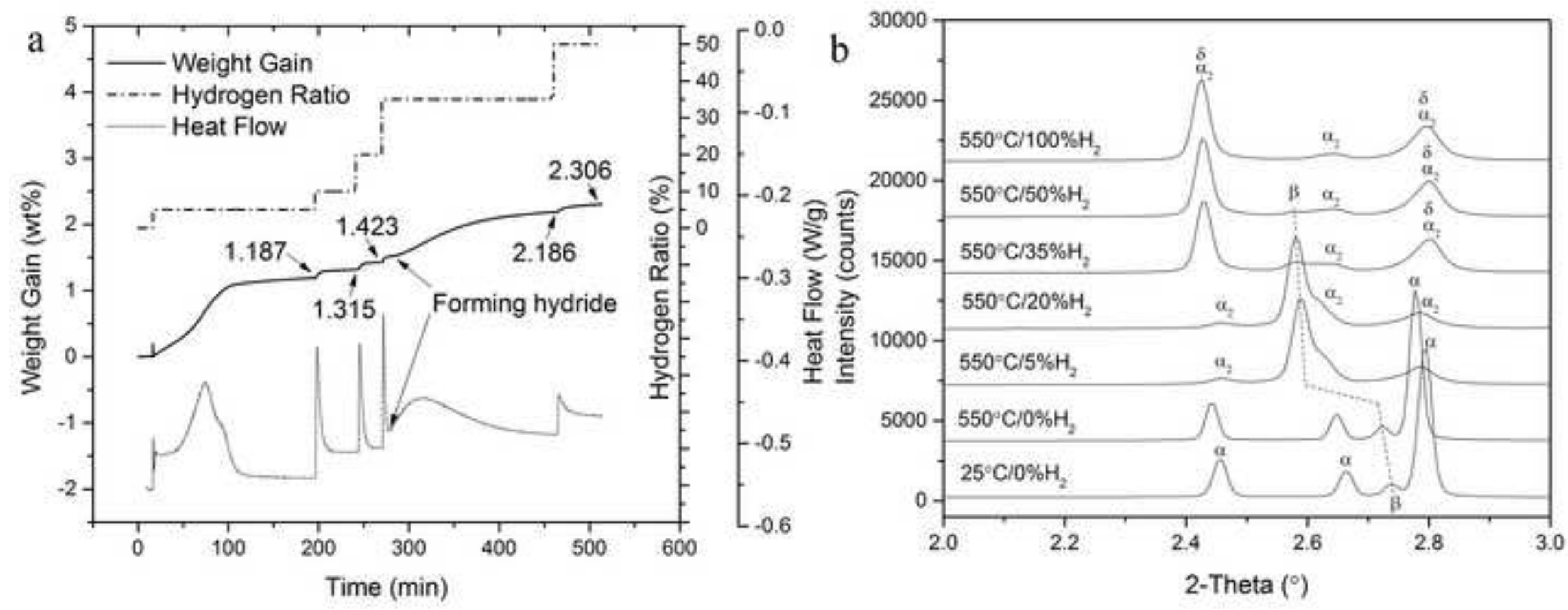


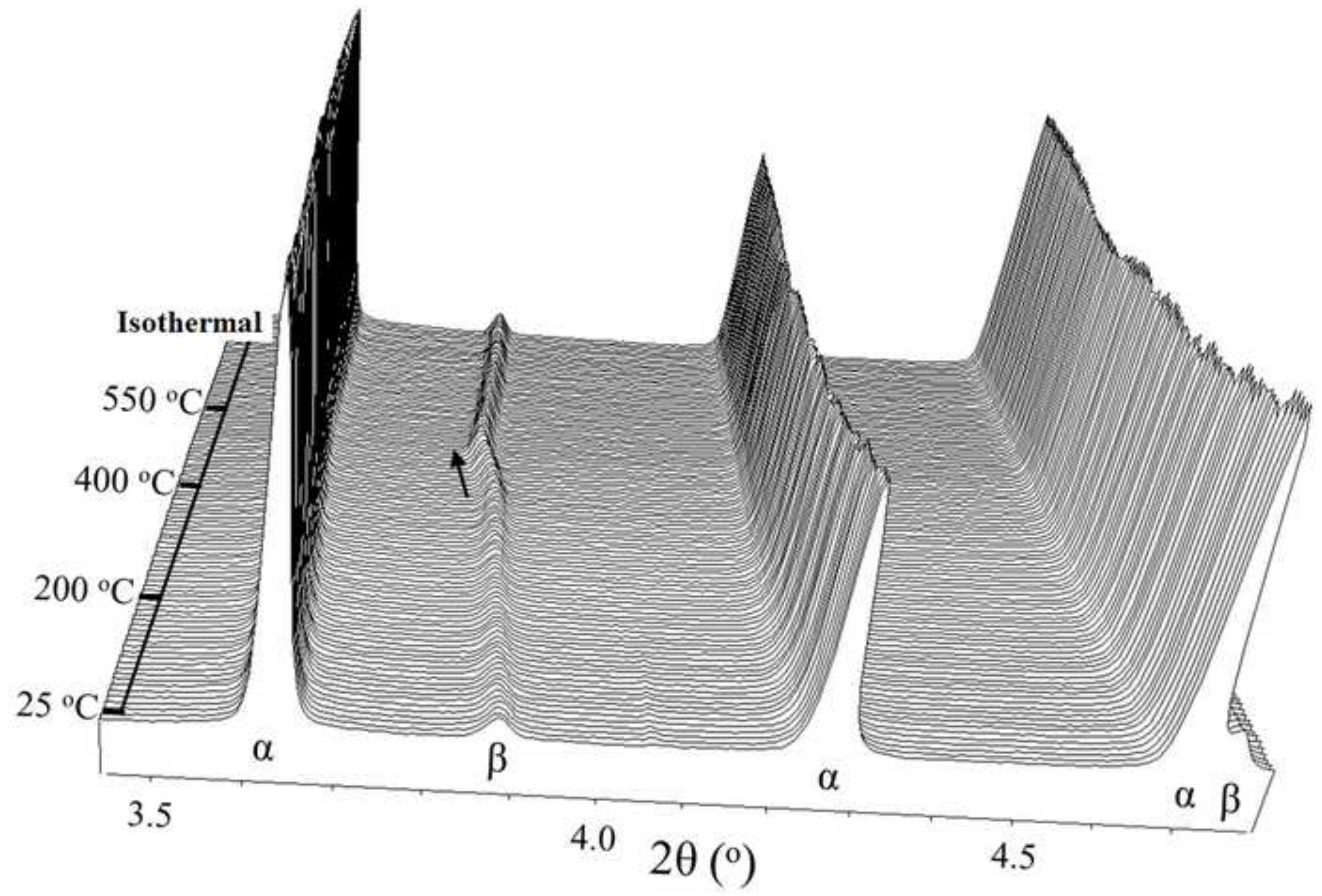




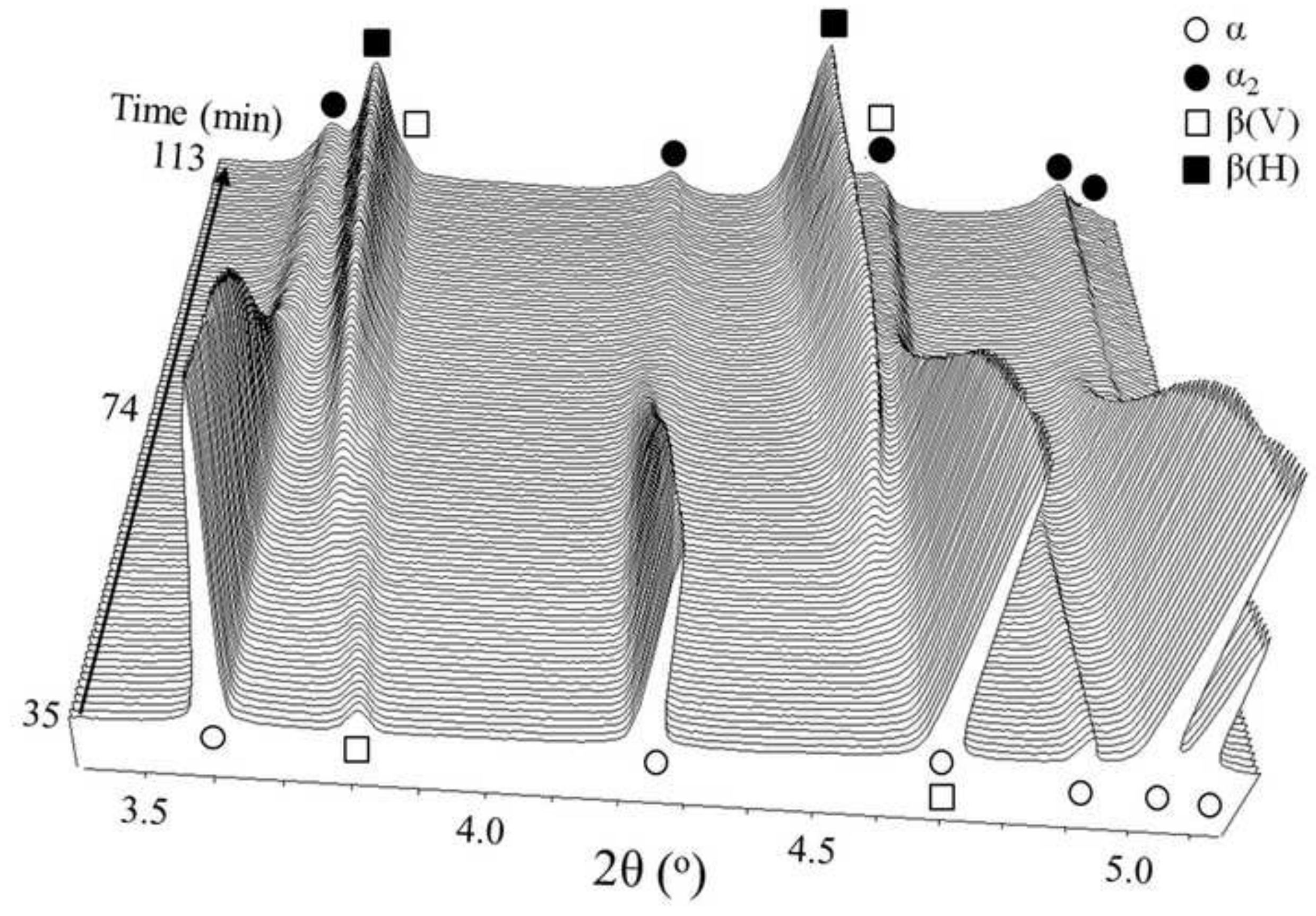



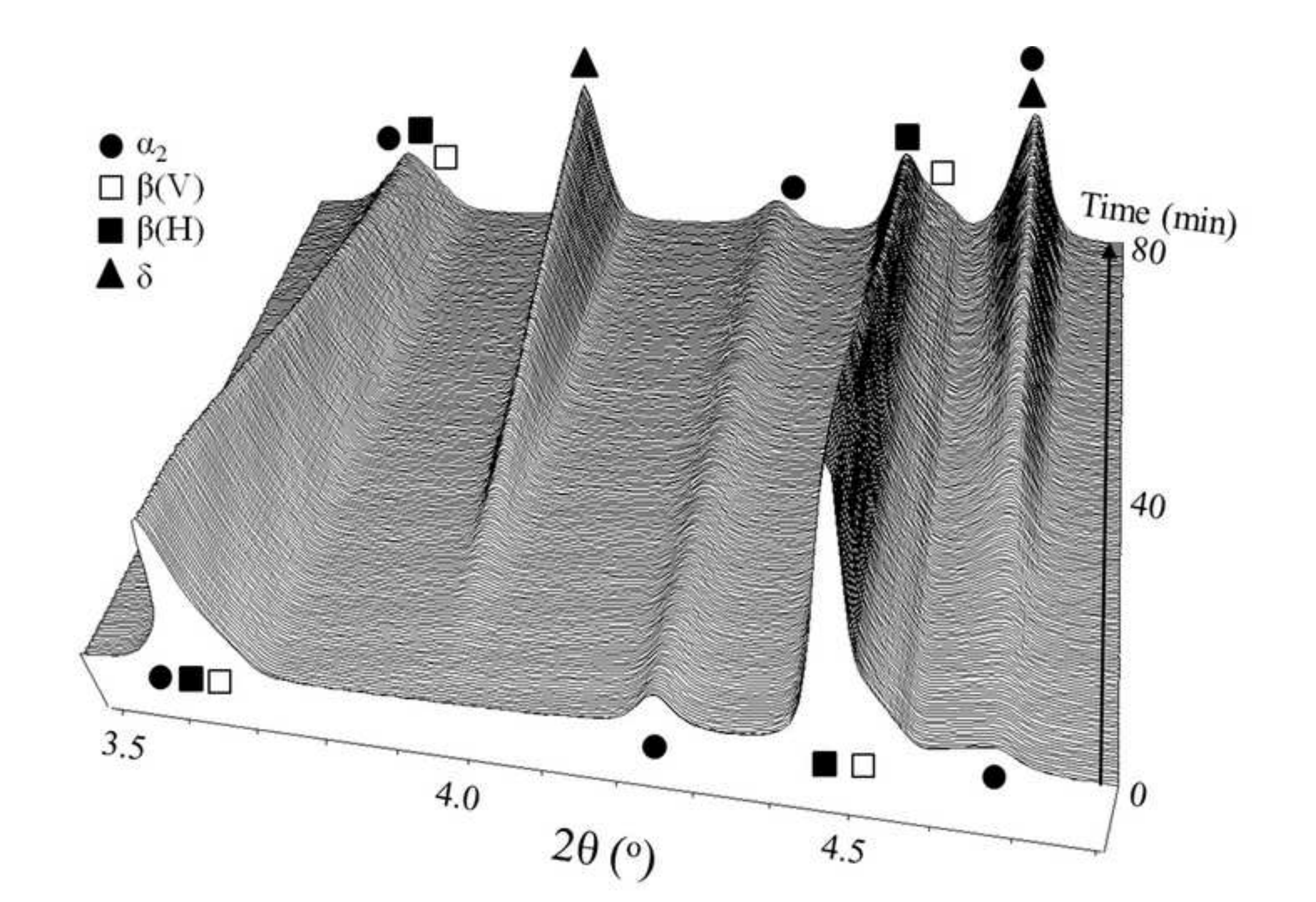

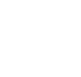

更

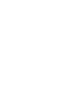

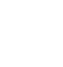

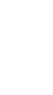



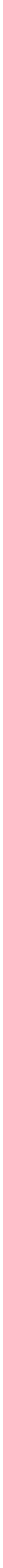
Figure(10)
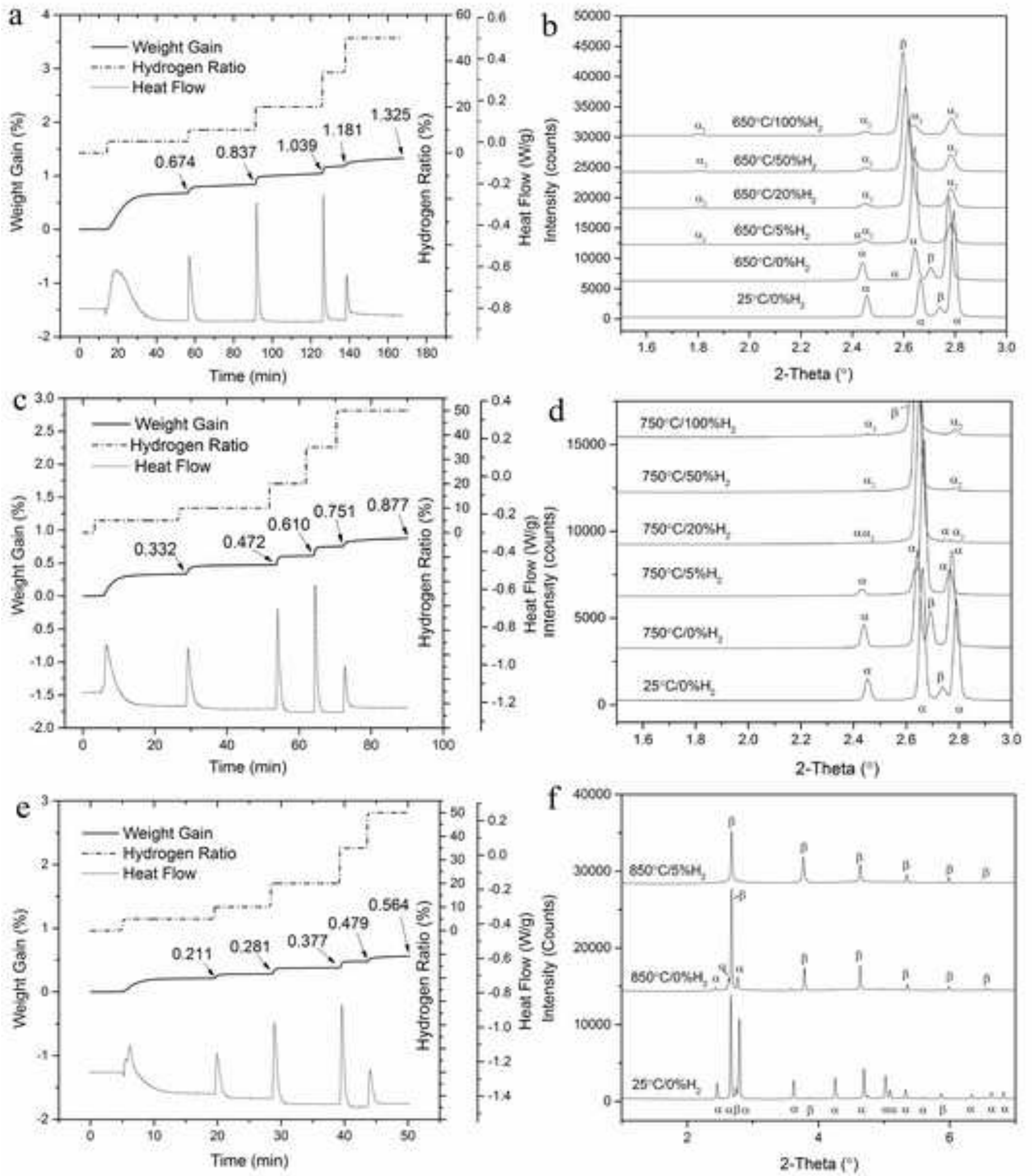

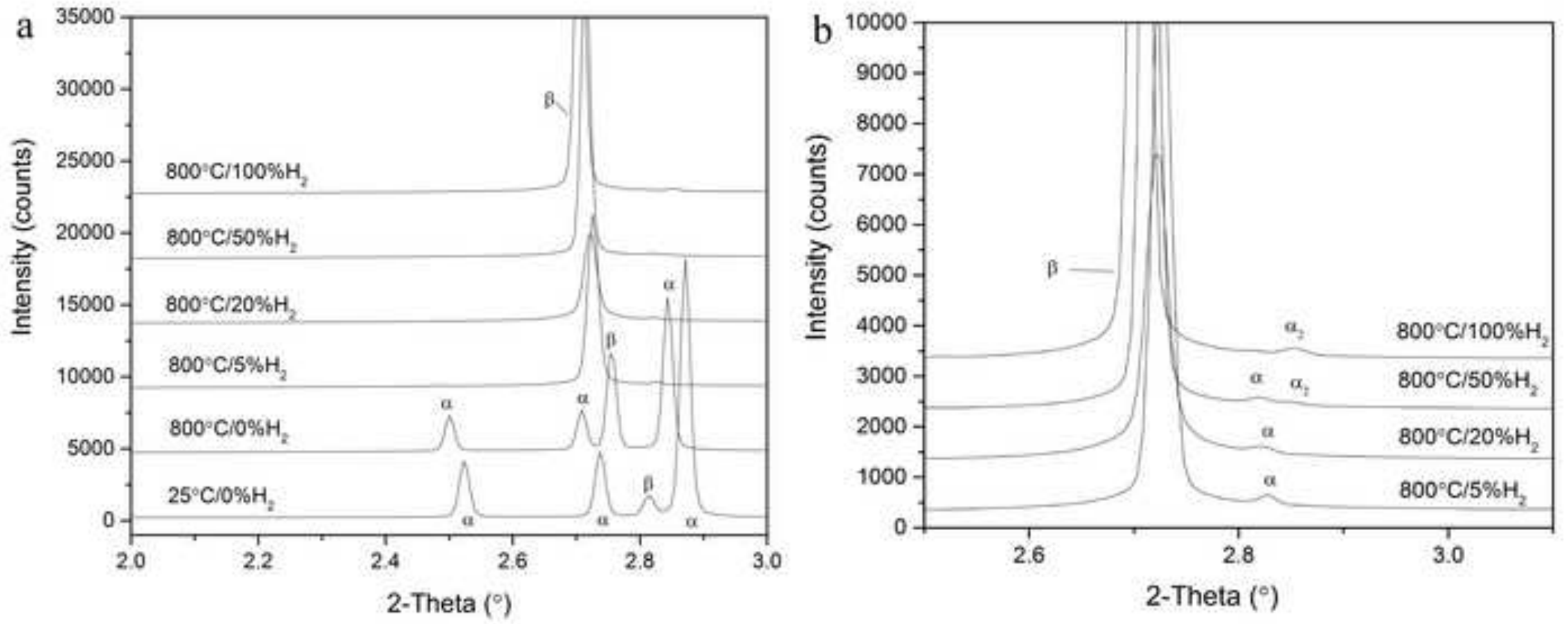


\section{Figure(12)
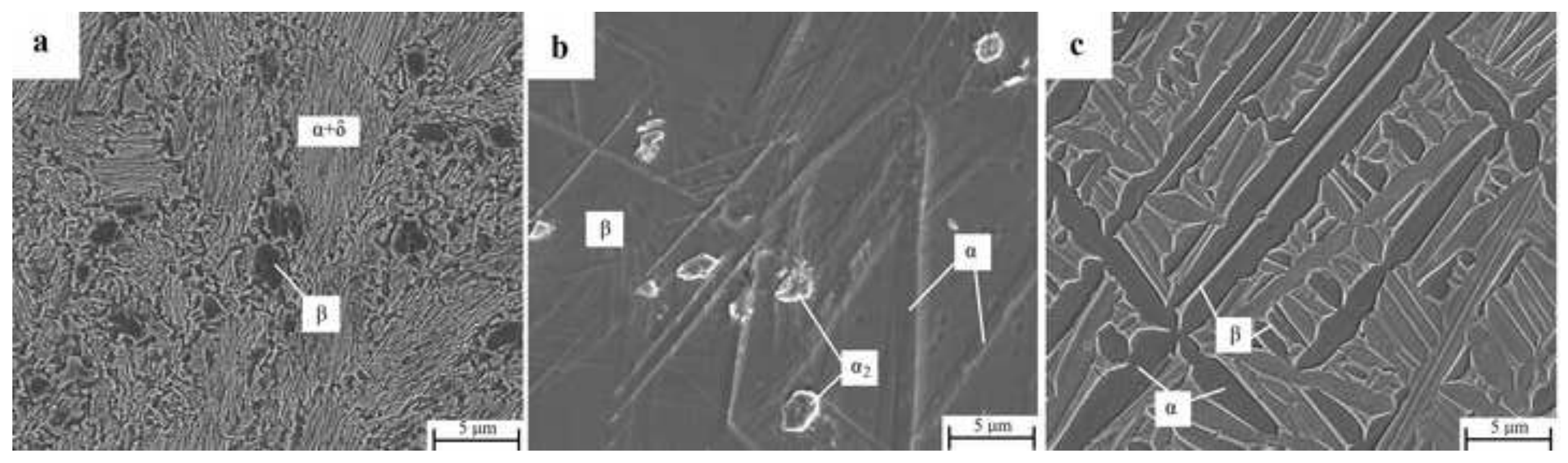
Hydrogen Content (wt.\%)

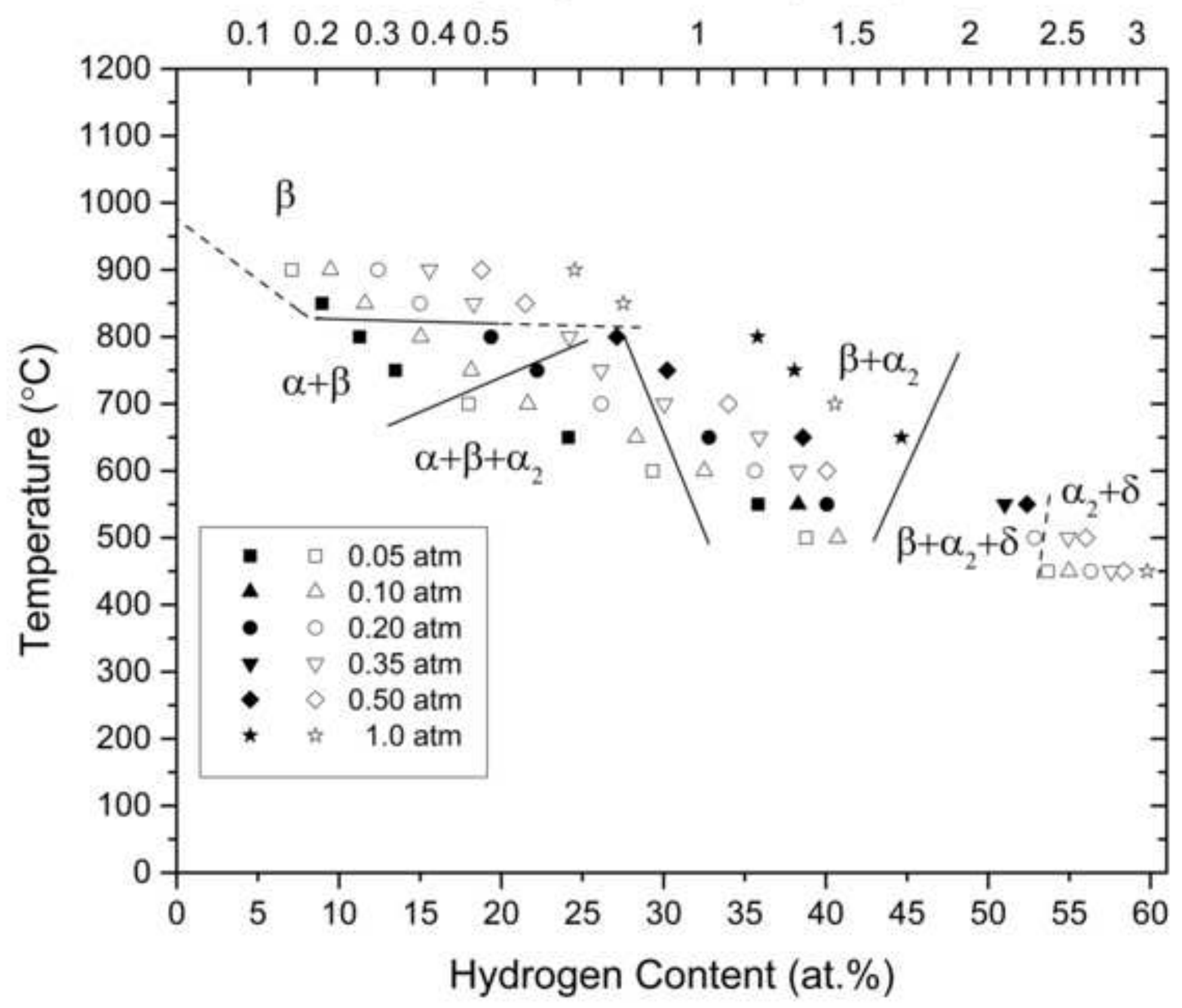




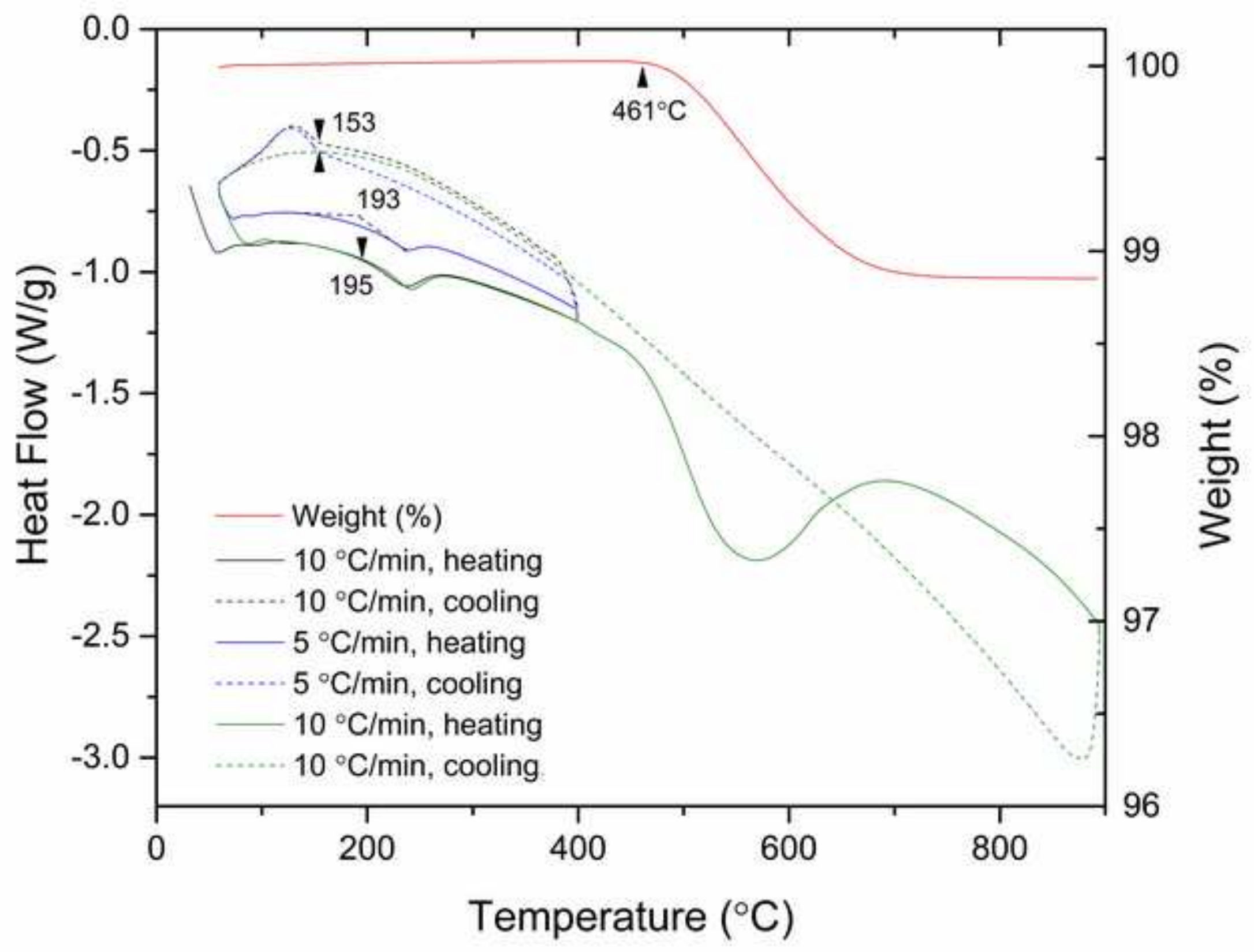




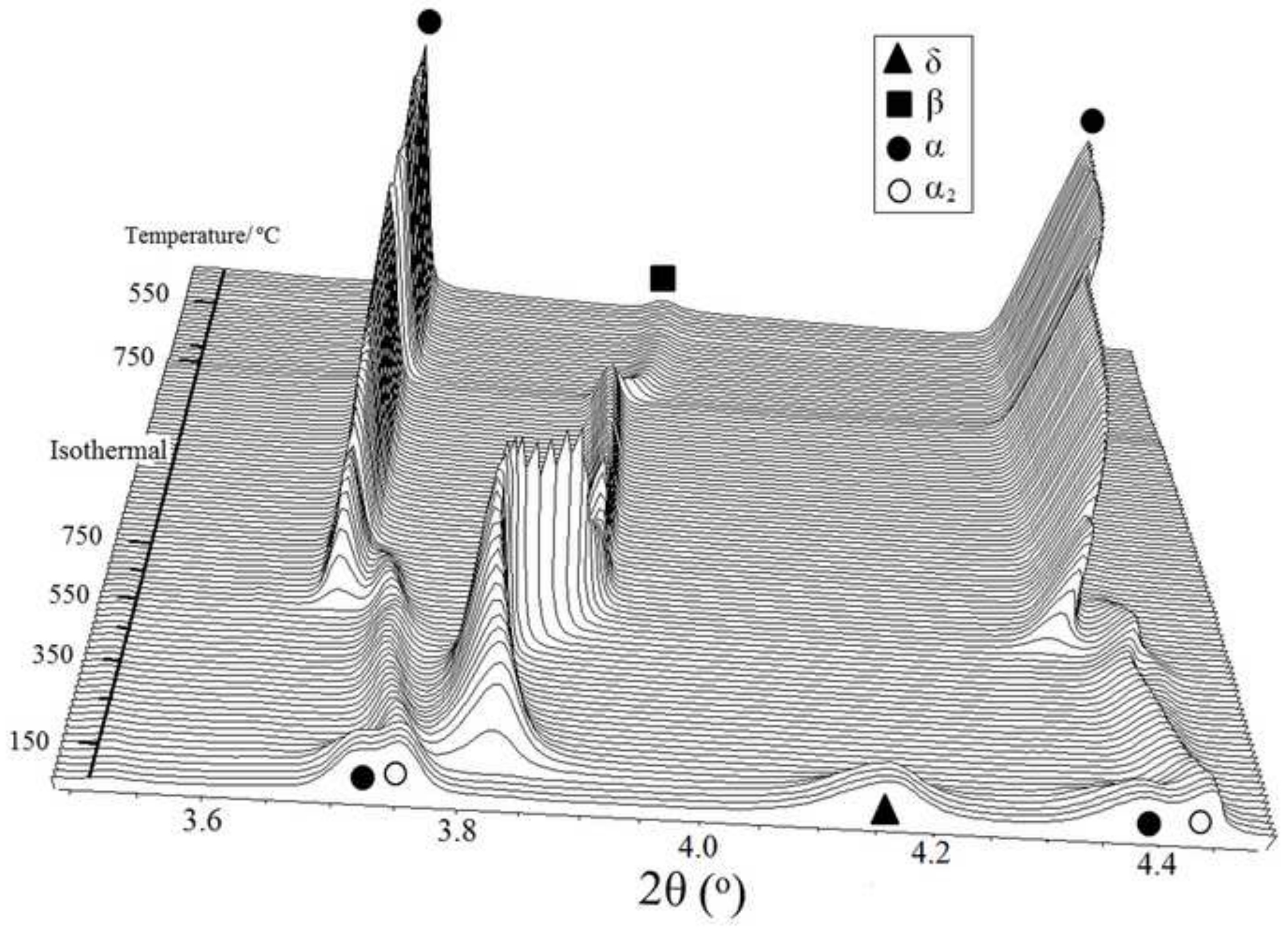



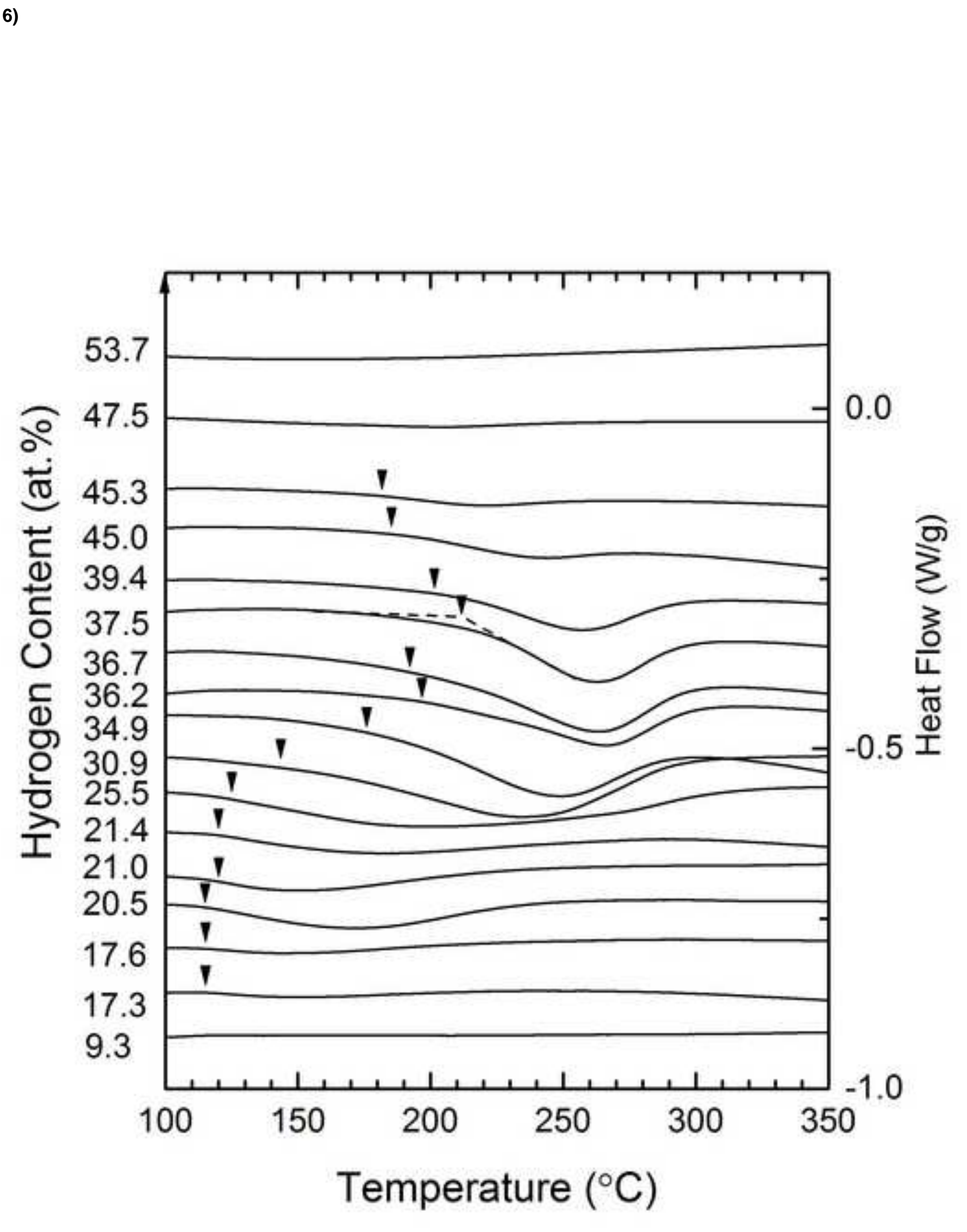

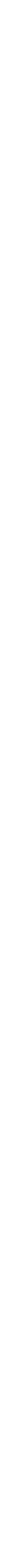
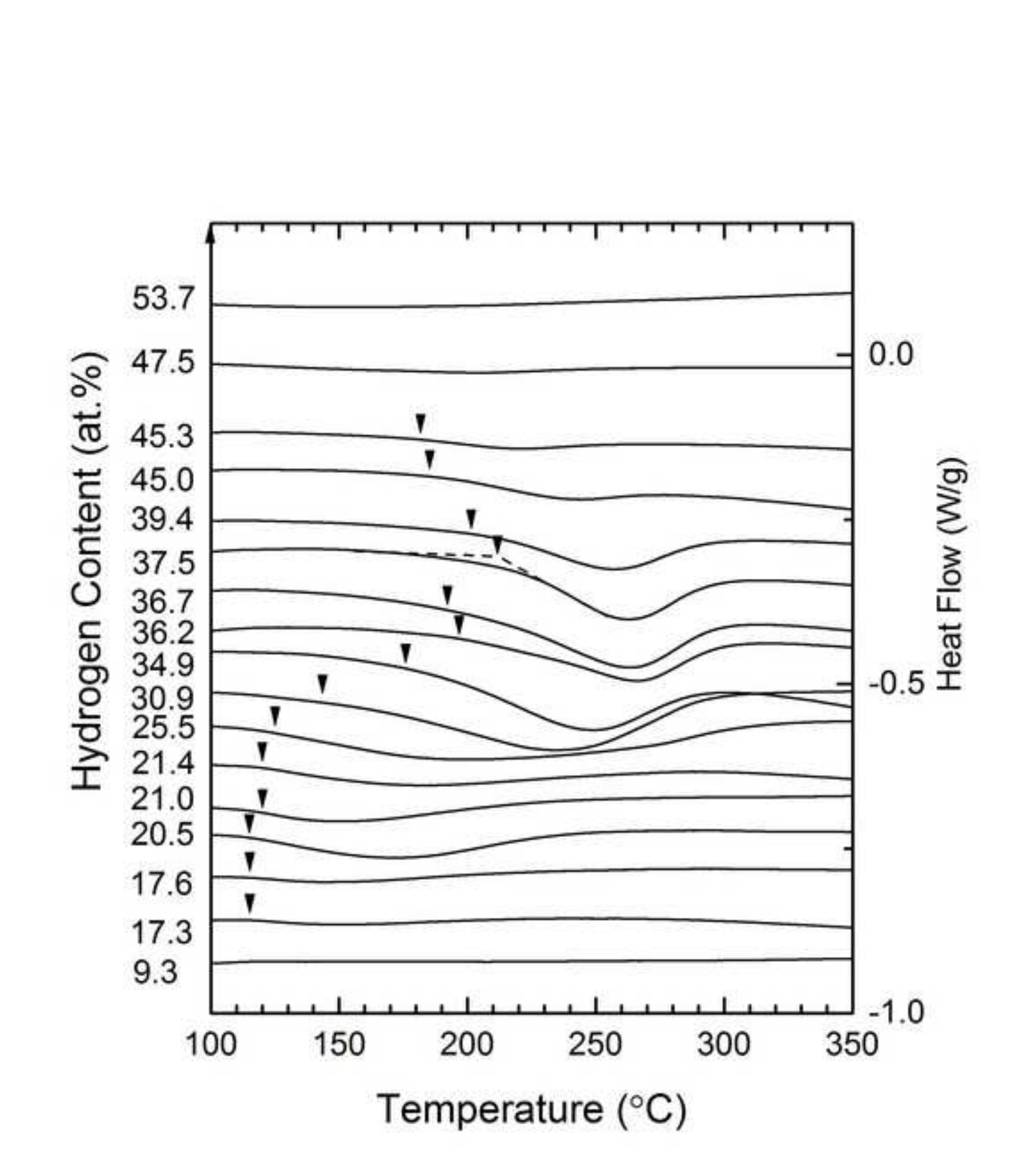
Hydrogen Content (wt.\%)

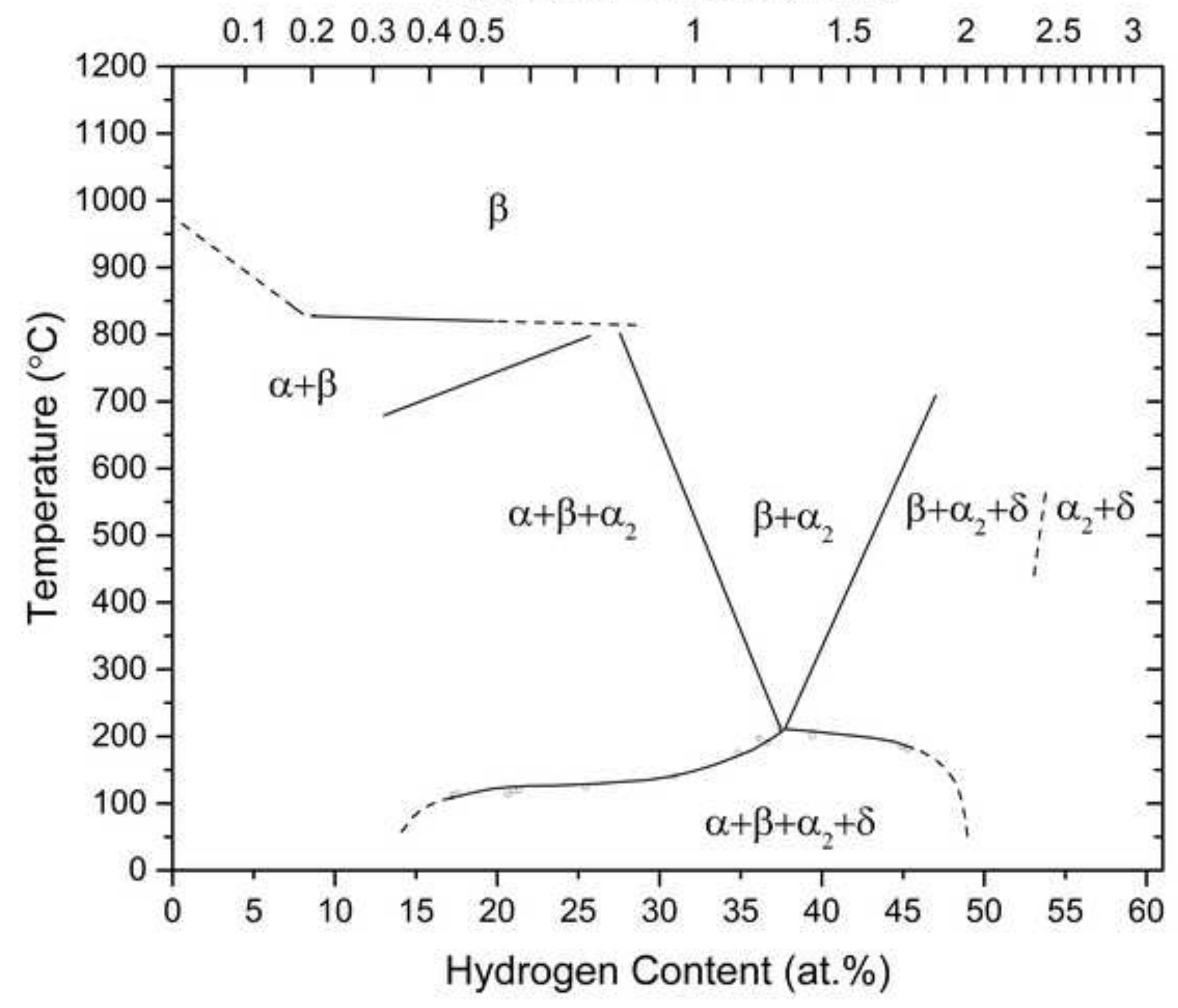




\begin{tabular}{ccccc}
\hline Temperature & $\mathrm{K}$ & $\mathrm{n}$ & $\mathrm{R}^{2}$ & $\mathrm{H}$ at.\% at $1.0 \mathrm{~atm}$ \\
\hline $900{ }^{\circ} \mathrm{C}$ & 24.517 & 0.4157 & 0.9984 & 24.52 \\
$850{ }^{\circ} \mathrm{C}$ & 27.518 & 0.3755 & 0.9993 & 27.52 \\
$800^{\circ} \mathrm{C}$ & 35.787 & 0.3822 & 0.9990 & 35.79 \\
$750{ }^{\circ} \mathrm{C}$ & 38.061 & 0.3385 & 0.9938 & 38.06 \\
$700{ }^{\circ} \mathrm{C}$ & 40.551 & 0.2724 & 0.9986 & 40.55 \\
$650{ }^{\circ} \mathrm{C}$ & 44.651 & 0.2018 & 0.9962 & 44.65 \\
$600{ }^{\circ} \mathrm{C}$ & 44.122 & 0.1348 & 0.9990 & 44.12 \\
$450{ }^{\circ} \mathrm{C}$ & 59.797 & 0.0364 & 0.9991 & 59.8 \\
\hline
\end{tabular}

